University of Windsor

Scholarship at UWindsor

$6-11-2019$

\title{
Calcium-Ion Batteries: Identifying Ideal Electrolytes for Next- Generation Energy Storage Using Computational Analysis
}

\author{
Mehdi Shakourian-Fard \\ Birjand University of Technology, Department of Chemical Engineering \\ Ganesh Kamath \\ Dalzierfiver LLC \\ S. Maryamdokht Taimoory \\ University of Windsor, Department of Chemistry and Biochemistry \\ John F. Trant \\ University of Windsor, Department of Chemistry and Biochemistry
}

Follow this and additional works at: https://scholar.uwindsor.ca/chemistrybiochemistrypub

Part of the Biochemistry, Biophysics, and Structural Biology Commons, and the Chemistry Commons

\section{Recommended Citation}

Shakourian-Fard, Mehdi; Kamath, Ganesh; Taimoory, S. Maryamdokht; and Trant, John F.. (2019). CalciumIon Batteries: Identifying Ideal Electrolytes for Next-Generation Energy Storage Using Computational Analysis. The Journal of Physical Chemistry C, 123 (26), 15885-15896.

https://scholar.uwindsor.ca/chemistrybiochemistrypub/146

This Article is brought to you for free and open access by the Department of Chemistry and Biochemistry at Scholarship at UWindsor. It has been accepted for inclusion in Chemistry and Biochemistry Publications by an authorized administrator of Scholarship at UWindsor. For more information, please contact scholarship@uwindsor.ca. 


\section{Notice:}

This document is the Accepted Manuscript version of a Published Work that appeared in final form in the The Journal of Physical Chemistry C, copyright (C) American Chemical Society after peer review and technical editing by the publisher. To access the final edited and published work see https://doi.org/10.1021/acs.jpcc.9b01655. 


\section{Computational Analysis}

5 Mehdi Shakourian-Fard ${ }^{\mathrm{a}^{*}}$, Ganesh Kamath ${ }^{\mathrm{b}}$, S. Maryamdokht Taimoory ${ }^{\mathrm{c}}$, John F. Trant ${ }^{\mathrm{c}}$

$6{ }^{a}$ Birjand University of Technology, Department of Chemical Engineering, Birjand, P.O. Box 7 97175/569, Iran.

$8{ }^{\mathrm{b}}$ Dalzierfiver LLC, 3500 Carlfied St, EL Sobrante, CA 94803, United States of America.

$9{ }^{\mathrm{c}}$ University of Windsor, Department of Chemistry and Biochemistry, Windsor, Ontario, N9B 3P4

10 Canada.

*Corresponding authors:

13 E-mail: shakourian@birjandut.ac.ir

14 E-mail: j.trant@uwindsor.ca
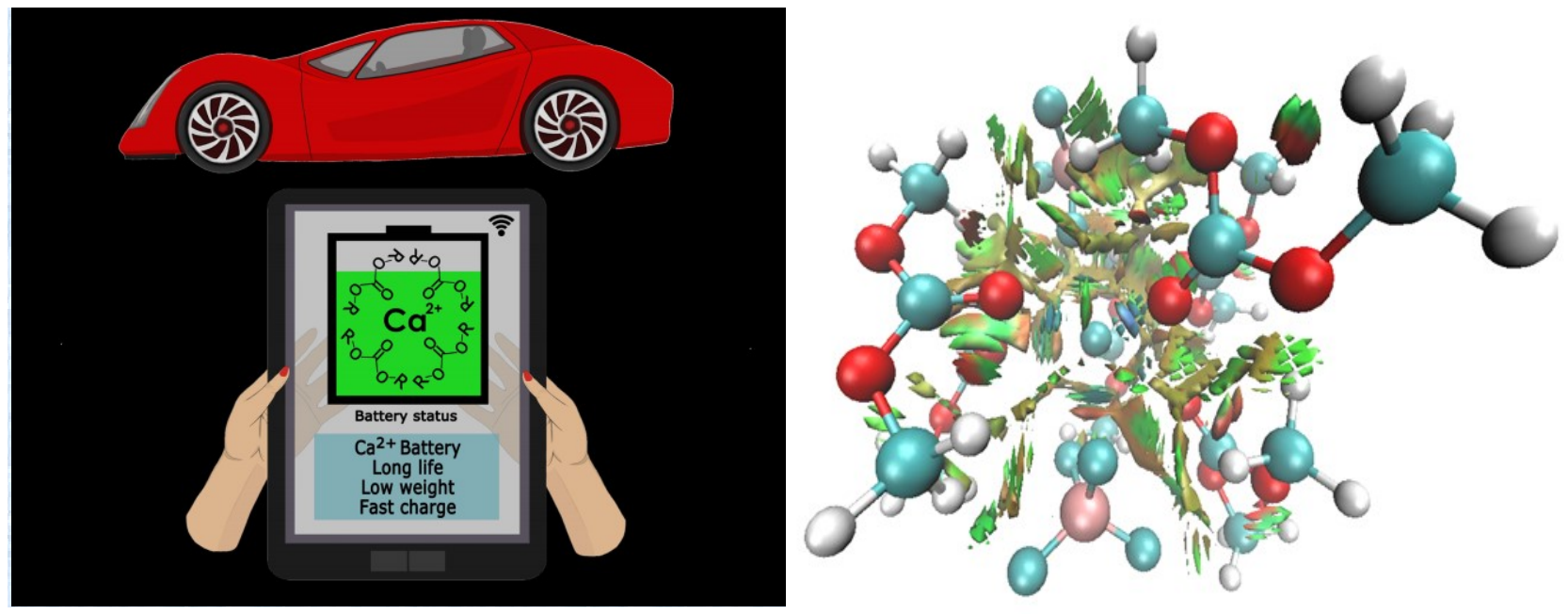


\section{Abstract}

2 Calcium ion batteries show promise as a high-density, next generation replacement for current 3 lithium ion batteries. The precise chemical structure of the carbonate electrolyte solvent has a 4 large impact on calcium battery efficacy. In this computational study, we have investigated the 5 solvation behavior of calcium tetrafluoroborate in both neat carbonates and carbonate mixtures 6 using combined molecular dynamics simulations and quantum mechanical calculations. Our 7 results indicate that both neat ethyl methyl carbonate and a mixture of ethylene carbonate and 8 diethyl carbonate show the highest free-energy of solvation for the $\mathrm{Ca}^{2+}$ ion, making them 9 likely candidates for further focus. The cation's interaction with the carbonyls of the 10 coordinating solvents, rather than those with the tetrafluoroborate counterions, play the 11 primary role in delocalizing the charge on $\mathrm{Ca}^{2+}$. Detailed calculations indicate that the HOMO12 LUMO energy gap $\left(E_{g}\right)$, electronic chemical potential $(\mu)$ and chemical hardness $(\eta)$ of the 13 calcium-carbonate complexes are directly proportional to the free energy of solvation of the 14 complex. Comparison of these observed trends with our previous results from $\mathrm{Li}^{+}, \mathrm{Na}^{+}$and $15 \mathrm{Mg}^{2+}$ ions show that this correlation is also observed in solvated magnesium ions, but not in 16 lithium or sodium salts. This observation should assist in the rational design of next generation 17 battery materials in the rational selection of additives, counterions, or electrolyte solvent. 


\section{Introduction}

Rechargeable lithium-ion batteries (LIBs) are the predominant commercial power

3 source for mobile phones, laptop computers, portable electronics, electric vehicles and

4 miscellaneous power devices due to their high energy density, good rechargeability and long

5 cycle-life. ${ }^{1,2}$ However, concerns surrounding future Li availability, cost, and safety have

6 prompted the search for competitive alternatives to rechargeable LIBs. ${ }^{3}$ Important

7 considerations for identifying alternative battery platforms include low-cost, improved safety,

8 environmental compatibility, charge retention, adequate energy density, long cycle-life, and

9 the rated capability. Recently, rechargeable batteries based on multivalent ions $\left(\mathrm{Ca}^{2+}, \mathrm{Mg}^{2+}\right.$, $\mathrm{Al}^{3+}$ ) have garnered significant attention as candidates for replacing $\mathrm{Li}$ ion batteries due to their higher energy density. ${ }^{4-9}$ This parameter is particularly important, as batteries are increasingly used in transportation, and the size and mass of the unit can be a limiting factor. Calcium-ion batteries are proposed as a particularly promising system due to their low cost, high natural electrode materials, electrolytes, and the interfacial dynamics of $\mathrm{Ca}^{2+}$ ions is required. While many recent studies have focused on the nature of potential electrode materials for $\mathrm{Ca}$-ion batteries, ${ }^{13-17}$ examinations of optimal electrolyte compositions have been far less common. ${ }^{18}$ Any suitable electrolyte must display sufficiently high conductivity, allow for high active species mobility, exhibit low dependence of conductivity on temperature, possess good electrochemical, mechanical and thermal stability, provide sufficient solubility for both electrolytes and non-electrolytes, have a low vapor pressure, and have a wide liquid temperature range. ${ }^{19-22} \mathrm{Ca}$-ion batteries normally employ organic solvents to dissolve the $\mathrm{Ca}$ salt. $\mathrm{Ca}\left(\mathrm{ClO}_{4}\right)_{2}, \mathrm{Ca}\left(\mathrm{BF}_{4}\right)_{2}, \mathrm{Ca}\left(\mathrm{PF}_{6}\right)_{2}$, and $\mathrm{Ca}($ bis(trifluoromethane)sulfonimide) salts have been the preferred calcium sources due to their high solubility. ${ }^{13,18}$ Any feasible electrolyte candidate must dissolve a high concentration of these salts to generate the requisite high

27 dielectric coefficient $(\varepsilon)$ while retaining a low enough viscosity to maintain excellent ionic conductivity and sufficient thermal and electrochemical stability. Carbonate electrolytes are particularly suited and are commonly used in current Li-ion batteries ${ }^{19}$ and remain the likeliest choice for the development of sodium and calcium-based batteries. ${ }^{13,18,23}$ 
There are two main classes of carbonate electrolytes: cyclic and acyclic (linear) carbonates and neither alone provides the required properties needed for an effective electrolyte.

The rate of the energy transfer in ion batteries is determined by the facility of ion transport 4 within the electrolyte. ${ }^{24}$ This ion transfer efficiency is controlled by two parameters, the 5 solvation of the ions by the electrolyte, and the rate of migration of the solvated ions to the 6 electrode surface. ${ }^{25}$ Generally, solvents with a high dielectric constant $(\varepsilon)$, such as the cyclic 7 carbonates, provide excellent solubility of the salt, but their highly polar nature also leads to 8 high viscosities decreasing the rate of ion transport. Conversely, linear carbonates, with a low $\varepsilon$, provide for fast ion transport but are also less able to solubilize the salt. Hence, in commercial ion batteries, a mixture of cyclic carbonates with high dielectric constant and acyclic 11 carbonates with low viscosity have generally been used to enhance both the solubility of salt and the mobility of ions, simultaneously. ${ }^{26}$ The ethylene carbonate (EC) as a cyclic carbonate with high dielectric constant $(\varepsilon=89.78)$ is usually employed in the mixture with various acyclic carbonates $^{19}$ because the presence of EC solvent in the mixture leads to form a very stable protective film (known as solid electrolyte interface (SEI)) on anode materials that prevents continuous electrolyte decomposition. ${ }^{18,19}$ In addition, the presence of linear carbonates such as DMC, EMC and DEC solvents in the binary mixtures usually lowers the charge voltage plateau and improves the reaction kinetics. ${ }^{19}$ The ideal electrolyte requires a careful analysis of this property trade-off to determine the proper mol fraction of the proper electrolytes. One recent experimental report explored a ternary system employing EC, DMC and EMC with slightly varying concentrations of calcium salts. ${ }^{27}$ This electrolyte was selected based on its success with lithium ion battery systems; however, it is unclear whether the same solvent effects that operate with lithium are relevant to calcium systems, the solvation may vary considerably as the cation-solvent interactions are dependent on the specific size and electronics of the system.

The nature of the anion-cation interaction also has a strong impact on the performance of a potential battery as it impacts the solvation structure and the solvent co-ordination number around the calcium center. ${ }^{28,29}$ The binding energy of these cation/anion complexes lies between those of the contact ion pair and the solvent separated pair. In a contact pair, conductance is poor, and this is observed if a lithium ion battery is prepared at too high a concentration-the solvated lithium is neutralized by the anion and the mobility under applied 
1 potential is significantly reduced. ${ }^{28} \mathrm{We}$ have found that $0.01 \mathrm{M}$ dilute solutions are useful for 2 the computational analysis to minimize this unfavorable process. In our previous studies into $3 \mathrm{LiPF}_{6},{ }^{30} \mathrm{NaClO}_{4},{ }^{31,32}$ and $\mathrm{Mg}\left(\mathrm{ClO}_{4}\right)_{2},{ }^{33}$ the cations did not interact with their anion at these 4 concentrations and were instead completely solvated by the carbonate electrolyte. However, 5 calcium has been reported to interact with the tetrafluoroborate anion. ${ }^{34}$ For this study we have 6 chosen $\mathrm{Ca}\left(\mathrm{BF}_{4}\right)_{2}$ as the model electrolyte. The choice of anion is based on experimental results:

7 calcium tetrafluoroborate is reported to be stable and compatible with battery chemistry unlike 8 the perchlorate salt. ${ }^{18,34}$

A series of experimental, ${ }^{35-37}$ quantum chemical $^{38-41}$ and molecular dynamics simulation ${ }^{30,40,42,43}$ studies have been performed to understand how the $\mathrm{Li}^{+}$ion is solvated by 11 both pure carbonates and mixtures of carbonates. However, as the solubility of each ion is 12 different, systems that perform well for Li-ion batteries are not necessarily appropriate for other types of batteries. Accordingly, to aid in the determination of appropriate electrolytes for 14 a Na-ion battery, we have previously reported on our integrated computational-experimental approach to rank-order the suitability of various cyclic and acyclic organic carbonates and their binary mixtures. ${ }^{31}$ In a second phase of this study, the solvation structure, coordination number around the $\mathrm{Na}^{+}$ions in both pure and binary mixture of carbonates, and the dynamic behavior of the $\mathrm{Na}^{+}$ions in these solvents were investigated using density functional theory (DFT) calculations. ${ }^{32}$ We have also carried out a similar investigation into $\mathrm{Mg}^{2+}$ ion solvation behavior by pure carbonate solvents and their binary mixtures at the electronic structure level using molecular dynamics simulations (MD) and density functional theory. ${ }^{33}$ Our studies strongly indicated that the preferred carbonate electrolytes for both $\mathrm{Na}^{+}$and $\mathrm{Mg}^{2+}$ ions are different from those that work best for $\mathrm{Li}^{+}$ions. Our theoretical work was in agreement with the experimental results reported by others. ${ }^{30-33}$ Furthermore, the dynamics of these ions in these solvents, the solvation structure of ions, and the coordination number around these ions in the carbonate solvents are quite different from one another and from $\mathrm{Li}^{+}$. Expanding these validated approaches to $\mathrm{Ca}^{2+}$ systems is a logical extension, especially considering that there is far less experimental evidence for the design of the ideal electrolyte with calcium ions. A computational study could assist in the identification of promising systems.

Ponrouch and coworkers recently applied a binary mixture of ethylene carbonate (EC) and propylene carbonate (PC) for the development of a new rechargeable battery technology 
1 using calcium anodes. ${ }^{18}$ This binary mixture forms surface passivation layers, known as a solid 2 electrolyte interphase (SEI) on the calcium anodes. However, the choice of solvent appears 3 empirical, as there is no published systematic investigation identifying optimal electrolytes for

4 Ca-ion batteries, and no scan of solvents has been reported. This study seeks to provide 5 theoretical insight into this question and predict this information. We have approached this

6 question using a series of the advanced theoretical analyses. These include combined7 molecular dynamics calculations and electronic structure calculations to predict the solvation 8 ability of the carbonates, including pure carbonate solvents (ethylene carbonate (EC), dimethyl 9 carbonate (DMC), diethyl carbonate (DEC), ethyl methyl carbonate (EMC), propylene carbonate (PC), vinyl carbonate (VC), butylene carbonate (BC)) and four equimolar binary 11 mixtures (EC:PC, EC:DMC, EC:EMC, and EC:DEC, see Figure S1 in the supporting 12 information). ${ }^{31}$ Choosing these binary mixtures allows for comparison with our previous 13 results while allowing for an analysis of the relative benefits of cyclic and acyclic carbonates 14 both in combination and alone. ${ }^{30-33}$ The choice of binary solvents is based on both Ponrouch's 15 choice of employing an EC:PC mixture in his recent report, and on our previous analyses of 16 other ion-batteries that employed these mixtures. The number of carbonate molecules 17 coordinated to each $\mathrm{Ca}^{2+}$ ion, and the coordination mode of the $\mathrm{Ca}^{2+}$ ion to the carbonate 18 molecules, were then determined. This was accompanied by comprehensive thermochemical

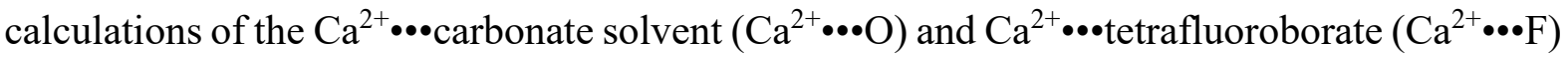
20 structures and their electronic properties using the M06-2X/6-311++G(d,p) level of theory. All 21 of these results are then compared to our previous reports that investigated the behavior of $\mathrm{Li}^{+}$, $22 \mathrm{Na}^{+}$and $\mathrm{Mg}^{2+}$ ions.

\section{2. Computational Methods and Details}

\section{2.1. Molecular Dynamics Simulations}

Molecular dynamics simulations were performed with NAMD version $2.9,{ }^{44,45}$ as carried out in our previous studies. ${ }^{30,32,33}$ Initial configurations for each system were generated 27 with Packmol in a simulation box with dimensions of $30 \times 30 \times 30 \AA^{3}$. The calcium ion, tetraborate anion and the cyclic and acyclic carbonates were modeled using a non-polarizable force field Charmm General Force Field (CGENFF). Energy minimization was performed on all systems for 500 steps using the steepest descent technique. Production runs (20.0 ns in an isobaric-isothermal ensemble at $1.0 \mathrm{~atm}$ and $300 \mathrm{~K}$ ) were performed. For all calculations, the 
1 temperature was maintained at $300 \mathrm{~K}$ using Langevin dynamics and a constant pressure was

2 maintained at 1.0 atm using the Nose-Hoover algorithm. A time step of $1.0 \mathrm{fs}$ was used for the

3 integration of Newton's equation of motion. Periodic boundary conditions were used in all the

4 three spatial coordinates. Long-range electrostatic interactions were calculated with Particle-

5 mesh Ewald algorithm. A switching function was applied for all Lennard-Jones interactions

6 at $12.5 \AA$ for a $14.0 \AA \AA$ cut-off.

7 According to the radial distribution functions, $\mathrm{g}(\mathrm{r})$, computed from our MD simulation

8 trajectories (Figure 1a), we find that the $\mathrm{Ca}^{2+}$ ion interacts strongly with the carbonyl $(\mathrm{C}=\mathrm{O})$

9 oxygen of the carbonate solvents at the average distance of $\sim 2.36 \AA$, which defines the width

10 of the first solvation shell, and weakly with the ether oxygen in the carbonate solvents at the

11 average distance of $\sim 4.5 \AA$. Resonance (charge delocalization) between the ether oxygen

12 atoms and $\mathrm{C}=\mathrm{O}$ group in the carbonate solvents increases the electron density on the oxygen

13 atom in the $\mathrm{C}=\mathrm{O}$ group and decreases it on the ether oxygen atoms. Therefore, the presence of

14 resonance increases the basicity of the oxygen atom in the $\mathrm{C}=\mathrm{O}$ group compared to the ether

15 oxygen atoms. Therefore, the $\mathrm{Ca}$ ion interacts strongly with the oxygen atom in the $\mathrm{C}=\mathrm{O}$ group

16 and has only a weak interaction with the ether oxygen atoms. The peak height from the radial

17 distribution function (RDF) of the interaction of the calcium ion with the carbonates can be

18 used as a metric to illustrate the strength of the calcium-carbonate interaction (Figure 1b). The

$19 \Delta \mathrm{G}_{(\text {sol })}$ values of the $\mathrm{Ca}^{2+}$-ion complexes computed from quantum mechanics (QM)

20 calculations correlate positively with the interaction strength of carbonyl groups in the first

21 solvation shell. 

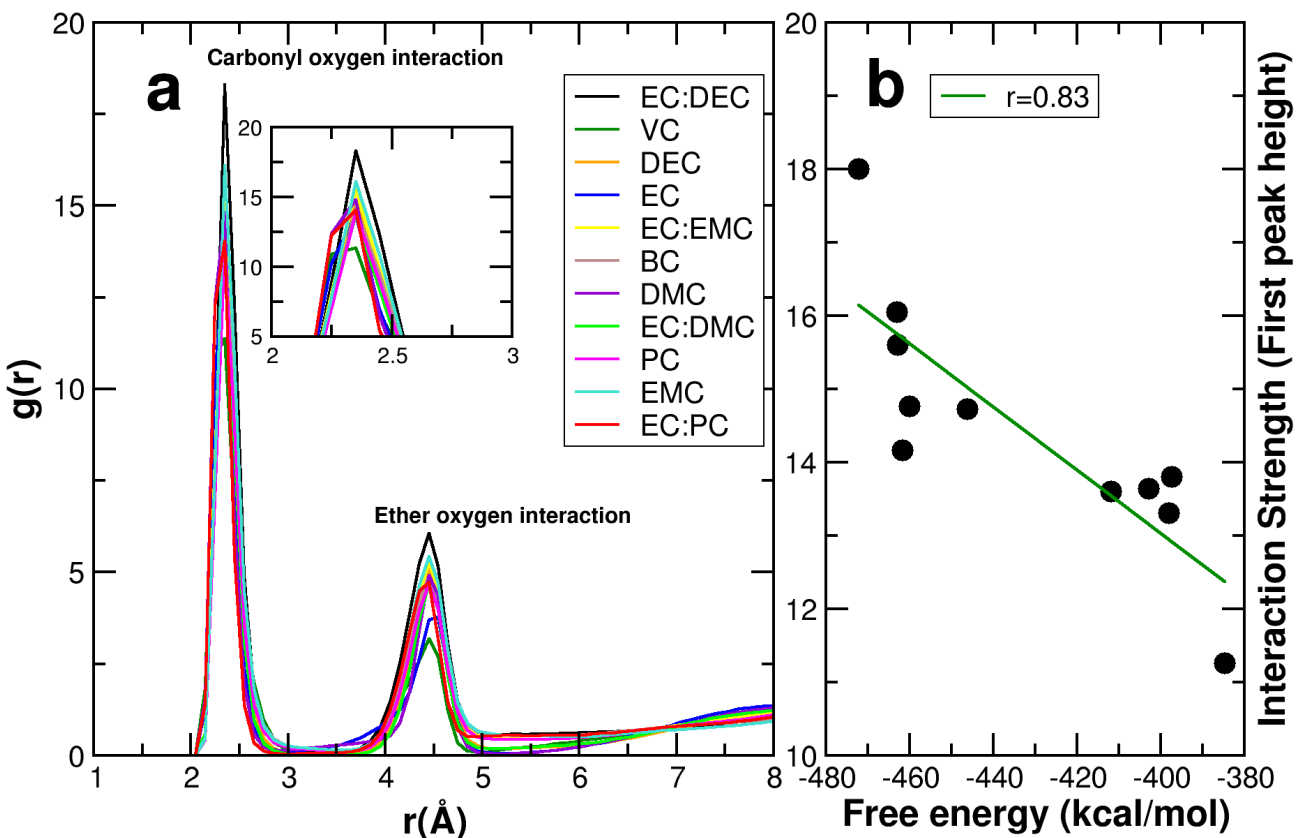

1 Figure 1. (a) Ion-oxygen radial distribution functions for $\mathrm{Ca}^{2+}$ solvated in the pure carbonates 2 and their binary mixtures, obtained from MD simulations. The population at $2.3 \AA$ is due to 3 interactions with the carbonyl oxygens, that at $4.4 \AA$ is due to interactions with the ether 4 oxygens, and those above $7 \AA$ are due to weak interactions with the subsequent solvation shells; 5 (b) Correlation between the free energy of solvation with the amplitude of the interaction 6 strength of carbonyl groups in the first solvation shell $(\mathrm{r}=0.83)$.

8 We computed the most probable clusters from this large and diverse population of $\sim 20,000$ 9 configurations obtained from the $20 \mathrm{~ns}$ isothermal-isobaric, NPT, molecular dynamics (MD) simulations. The maximum probable cluster size for each carbonate system was determined according to our previously published protocol. ${ }^{32}$ Based on a distance criterion of $3.0 \AA$ for

$12 \mathrm{Ca}^{2+}-\mathrm{O}$ (oxygen of the carbonate), we calculated a variety of Ca-carbonate coordinated 13 clusters. The $3.0 \AA$ corresponds to the minimum in the first solvation peak as seen in the radial 14 distribution function for interaction of the carbonates with the calcium ion. We then computed 15 the number integrals for $\mathrm{Ca}^{2+}$ ion interaction with carbonates and found that the oxygen coordination number corresponds to the cluster size of the Ca-carbonate complex (Figure S2).

17 Figure $\mathrm{S} 3$ provides the distribution of such various size $\mathrm{Ca}^{2+}$-coordinated carbonate clusters 18 for the seven neat carbonates and the four associated equimolar mixtures: each carbonate 19 prefers a particular cluster size. For EC, PC and VC, we saw that the most populated clusters 
1 corresponded to size 8. In $\mathrm{BC}$ and $\mathrm{DMC}$, cluster sizes of 6 dominate the entirety of the $20 \mathrm{~ns}$

2 simulation runs. For the equimolar mixture of EC:EMC, we observed a cluster size of 9.

3 Similarly, the cluster sizes were determined for the calcium in other carbonates and their

4 equimolar mixtures. These cluster sizes are stable throughout the entirety of the simulation

5 with $>70 \%$ life-time occurrence and are much larger in size than those we observed in any of

$6 \mathrm{Mg}^{2+}, \mathrm{Li}^{+}$, or $\mathrm{Na}^{+}$-coordinated carbonate clusters. We also noticed that the tetraborate anion

7 interacts strongly with the calcium ion as seen from Figure S4. This is in stark contrast to $\mathrm{Li}^{+}$,

$8 \mathrm{Na}^{+}$and even $\mathrm{Mg}^{2+}$ where the cation-anion interaction was not significant throughout the entire

9 simulation (Figure S5).

10 The most favourable $\mathrm{Ca}^{2+}$-carbonate cluster configurations obtained from the $\mathrm{MD}$ 11 simulations were then subjected to detailed thermochemistry calculations using a first principle

12 DFT method to better understand the electronic properties in the $\mathrm{Ca}^{2+}$-coordinated carbonate 13 clusters.

\section{2.2. Density Functional Quantum Chemical Calculations}

Quantum chemical calculations to further investigate the structural and electronic properties of the maximum probable cluster size for each system were performed using the Gaussian 09 package. ${ }^{46}$ Full optimization, energetic, structural and electronic analyses were carried out using M06-2X (Minnesota 2006 functional with double Hartree-Fock exchange) developed by Truhlar and coworkers, ${ }^{47,48}$ in combination with the $6-311++\mathrm{G}(\mathrm{d}, \mathrm{p})$ basis set. This functional has already been used for metal-ion battery systems in the literature and has

21 been repeatedly shown to accurately represent non-covalent interactions. ${ }^{32,33,48-51}$ A vibrational

22 frequency calculation was carried out for each structure to ensure the absence of imaginary

23 frequencies, confirming each structure as a minimum on the potential energy surface. Zero24 point vibrational energies were determined for each optimized geometry and were incorporated into the binding energy calculations. The binding energy $\left(\Delta \mathrm{E}_{\mathrm{b}}\right)$ of $\mathrm{Ca}^{2+} \cdot \bullet$ carbonate solvent systems was calculated according to equation 1:

$$
\Delta \mathrm{E}_{\mathrm{b}}=\mathrm{E}_{(\text {Complex })}-\left(\mathrm{n}_{1} \cdot \mathrm{E}_{(\text {Carbonate })}+\mathrm{n}_{2} \cdot \mathrm{E}_{\left(\mathrm{BF}^{-}\right)^{-}}+\mathrm{E}_{\left(\mathrm{Ca}^{2+}\right.}{ }_{\text {ion })}\right)
$$

where $n_{1}$ represents the number of interacting carbonate solvent molecules and $n_{2}$ the number of coordinating $\left[\mathrm{BF}_{4}\right]^{-}$anions. $\mathrm{E}_{(\text {Carbonate })}, \mathrm{E}_{\left(\mathrm{BF}^{-}\right)}, \mathrm{E}_{\left(\mathrm{Ca}^{2+}\right.}{ }^{2+}$ ion), and $\mathrm{E}_{(\text {Complex })}$ are the energies of the 31 carbonate solvent, the $\left[\mathrm{BF}_{4}\right]^{-}$anion, the $\mathrm{Ca}^{2+}$ ion, and the complete solvated complex 
1 respectively. Binding energy values were corrected for basis set superposition errors (BSSEs)

2 using the counterpoise method suggested by Boys and Bernardi. ${ }^{52}$

3 The enthalpy of solvation $\left(\Delta \mathrm{H}_{(\mathrm{sol})}\right)$ and the free energy of solvation $\left(\Delta \mathrm{G}_{(\mathrm{sol})}\right)$ of the

4 complexes were calculated at $298.15 \mathrm{~K}$ using equation 2:

$$
\Delta \mathrm{X}_{(\mathrm{sol})}=\mathrm{X}_{(\text {Complex })}-\left(\mathrm{n} \cdot \mathrm{X}_{(\text {Carbonate })}+\mathrm{n} \cdot \mathrm{X}_{\left(\mathrm{BF}^{-}\right)^{-}}+\mathrm{X}_{\left(\mathrm{Ca}^{2+}\right.}{ }_{\text {ion })}\right)
$$

$\mathrm{X}=\mathrm{H}$ (enthalpy) or $\mathrm{G}$ (free energy)

7 where $\mathrm{X}_{(\text {Complex) }}$ is the free energy (or enthalpy) of the complex of $\mathrm{Ca}^{2+}$ ion with the carbonate 8 solvents and $\left[\mathrm{BF}_{4}\right]^{-}$anions, $\mathrm{X}_{(\text {Carbonate) }}$ is the free energy (or enthalpy) of the carbonate solvents, $\left.9 \mathrm{X}_{(\mathrm{BF} 4)}\right)^{-}$and $\mathrm{X}_{(\mathrm{Ca}}{ }^{2+}$ ion) are the free energy (or enthalpy) of the $\left[\mathrm{BF}_{4}\right]^{-}$anions and $\mathrm{Ca}^{2+}$ ion, 10 respectively, and $\mathrm{n}$ is the number of carbonate solvents and $\left[\mathrm{BF}_{4}\right]^{-}$anions in the complexes.

11 The entropy (S) of solvation $\left(\Delta \mathrm{S}_{(\mathrm{sol})}\right)$ was also calculated at $298.15 \mathrm{~K}$ using the calculated $12 \Delta \mathrm{H}_{(\mathrm{sol})}$ and $\Delta \mathrm{G}_{(\mathrm{sol})}$ values, according to the following equation:

$$
\Delta \mathrm{S}_{(\mathrm{sol})}=\frac{\left(\Delta \mathrm{H}_{(\mathrm{sol})}-\Delta \mathrm{G}_{(\mathrm{sol})}\right)}{298.15}
$$

Further analysis using quantum chemical calculations were employed to provide improved characterization of the electronic structure of these complexes. Second-order perturbation theory analysis of the Fock matrix was carried out to evaluate the donor-acceptor interactions $\left(\mathrm{Ca}^{2+} \bullet \bullet \mathrm{O}\right.$ and $\left.\mathrm{Ca}^{2+} \bullet \bullet \mathrm{F}\right)$ using a natural bond orbital (NBO) methodology. In these interactions, electrons partially delocalize from the localized natural bond orbitals of the idealized Lewis structure into an empty non-Lewis orbital. For each donor NBO (i) and acceptor NBO $(\mathrm{j})$, the stabilization energy $E^{(2)}$ associated with the delocalization $\mathrm{i} \rightarrow \mathrm{j}$ is 21 estimated by the following equation ${ }^{53}$ :

$$
\mathrm{E}^{(2)}=-2 \frac{\langle\mathrm{i}|\hat{\mathrm{F}}| \mathrm{j}\rangle^{2}}{\varepsilon_{j}-\varepsilon_{i}}
$$

22 where $\varepsilon_{j}$ and $\varepsilon_{i}$ are NBO orbital energies and $\hat{\mathrm{F}}$ is the Fock operator.

A natural population analysis (NPA) ${ }^{54}$ was conducted using a NBO analysis ${ }^{53}$ at the 24 M06-2X/6-311++G(d,p) level of theory. This quantifies the magnitude of the charge transfer 25 between the $\mathrm{Ca}^{2+}$ ion and its associated carbonate solvent and $\left[\mathrm{BF}_{4}\right]^{-}$anion molecules. The 26 Wiberg bond index (WBI), ${ }^{55,56}$ as a criterion for determining the bond order between two 27 atoms, was calculated for the interactions between the $\mathrm{Ca}^{2+}$ ion and the $\mathrm{O}$ atom of the carbonyl 
1 groups of the carbonate solvents and the $\mathrm{F}$ atoms of $\left[\mathrm{BF}_{4}\right]^{-}$anions to evaluate the strength of 2 the interaction.

3 The quantum theory of atoms in molecules (QTAIM) ${ }^{57}$ analysis was also used to 4 characterize the nature and strength of interaction of $\mathrm{Ca}^{2+}$ ion with both the carbonate solvents 5 and the $\left[\mathrm{BF}_{4}\right]^{-}$anions using the AIM2000 program. ${ }^{58}$ The nature of these interactions was

6 further analyzed using noncovalent interaction (NCI) plots as implemented in Multiwfn-3.2 7 and VMD. ${ }^{59,60}$ The HOMO and LUMO orbital energies, the HOMO-LUMO energy gap ( $\mathrm{E}_{\mathrm{g}}$ ), 8 and the global molecular descriptors such as electronic chemical potential $\left(\mu ; \mu=\left(\mathrm{E}_{\mathrm{HOMO}}+\right.\right.$ $\left.\left.9 \mathrm{E}_{\mathrm{LUMO}}\right) / 2\right)$, chemical hardness $\left(\eta ; \eta=\left(\mathrm{E}_{\text {LUMO }}-\mathrm{E}_{\text {Hомо }}\right) / 2\right)$, global softness $(S ; S=1 / \eta)$ and 10 electrophilicity index $\left(\omega ; \omega=\mu^{2} / 2 \eta\right)^{61-63}$ were calculated for the carbonate solvents and their 11 complexes with the $\mathrm{Ca}^{2+}$ ion using Koopmans' theorem. ${ }^{64}$

\section{Results and Discussion}

3.1. Determination of the Optimized Geometries and Energetics of Carbonate-Solvated

\section{$\mathrm{Ca}^{2+}$-Ion Complexes}

MD simulations provided preferred initial configurations of the calcium ion complexes formed in $\mathrm{EC}, \mathrm{VC}, \mathrm{PC}, \mathrm{BC}, \mathrm{DMC}, \mathrm{EMC}, \mathrm{DEC}$ and the binary mixtures of $\mathrm{EC}: \mathrm{PC}, \mathrm{EC}: \mathrm{DMC}$, EC:EMC and EC:DEC. The DFT calculations were carried out using the M06-2X/6$311++\mathrm{G}(\mathrm{d}, \mathrm{p})$ method to describe the solvation behavior of $\mathrm{Ca}^{2+}$ ion in the various carbonate solvents as this level of theory has proven sufficient for previous studies. ${ }^{30,33,65} \mathrm{We}$ were able to determine the strength and nature of the ion's interaction with carbonate solvents and then use these values to rank order the $\mathrm{Ca}^{2+}$ solvation capacity of the carbonate solvents and binary mixtures. These optimized geometries, along with the $\mathrm{Ca}^{2+} \bullet \bullet \cdot \mathrm{O}$ and $\mathrm{Ca}^{2+} \bullet \bullet \cdot \mathrm{F}$ distances (in $\AA$ ) associated with the interaction of $\mathrm{Ca}^{2+}$ ion with carbonate solvents and the $\left[\mathrm{BF}_{4}\right]^{-}$counterions in the first solvation shell, are provided as Figures S6 and S7.

Unlike the $\mathrm{Li}^{+}, \mathrm{Na}^{+}$and $\mathrm{Mg}^{2+}$ ions we had previously examined, ${ }^{30,32,33}$ the solvation structure of the $\mathrm{Ca}^{2+}$ ion is highly solvent dependent. We found that the $\mathrm{Ca}^{2+}$ ion is solvated by 4-8 carbonate solvents and either one or two $\left[\mathrm{BF}_{4}\right]^{-}$anions depending on the solvent. The average number of carbonate solvents and anions in the first coordination shell of the lowest energy complex is provided in Table 1. The optimized geometries in Figures S6 and S7 show that the $\left[\mathrm{BF}_{4}\right]^{-}$anions form mono-coordinated complexes with the $\mathrm{Ca}^{2+}$ ion in the $\mathrm{Ca}^{2+}(\mathrm{EC})$, 
$1 \mathrm{Ca}^{2+}(\mathrm{VC}), \quad \mathrm{Ca}^{2+}(\mathrm{PC}), \quad \mathrm{Ca}^{2+}(\mathrm{BC}), \quad \mathrm{Ca}^{2+}(\mathrm{DMC}), \quad \mathrm{Ca}^{2+}(\mathrm{EC}: \mathrm{PC}), \quad \mathrm{Ca}^{2+}(\mathrm{EC}: \mathrm{DMC}) \quad$ and

$2 \mathrm{Ca}^{2+}(\mathrm{EC}: \mathrm{DEC})$ complexes, whereas in the $\mathrm{Ca}^{2+}(\mathrm{EMC}), \mathrm{Ca}^{2+}(\mathrm{DEC})$ and $\mathrm{Ca}^{2+}(\mathrm{EC}: \mathrm{EMC})$

3 complexes, the calcium ion forms a bifurcated interaction using two $\mathrm{F}$ atoms on two different

4 counterion molecules. Whether the anion is mono-coordinated or bi-coordinated to the $\mathrm{Ca}^{2+}$ is

5 determined by the number and geometry of solvent and anion molecules in the coordination

6 sphere of a given solvent-calcium combination. Importantly, the anion is part of this first

7 solvation shell. This was not seen for the other cations.

8 There are several factors that contribute to this different behavior. Calcium is the lone

9 fourth row ion in this series and has a full $3 p$ shell. This allows for charge distribution

10 unavailable to the other ions and changes the solvent-ion distances. The average carbonate-ion

11 distance is approximately $2.4 \AA$ for these calcium clusters compared to 2.2, 2.0 and $1.9 \AA$ for

12 sodium, magnesium and lithium respectively. ${ }^{30,32,33}$ With this greater space provided by this

13 longer interaction length, there are additional possibilities for the different solvents to organize

14 around the calcium center. A second key factor involves the higher cell potential obtained with

15 calcium as opposed to magnesium as the stronger coulombic interactions between calcium and

16 the carbonate result in higher viscosities and consequently lower ion mobility than that

17 observed for lithium or sodium cations. ${ }^{66}$ These stronger interactions with the solvent would

18 suggest that electrolyte choice might prove more important for calcium compared to the other

19 ions where this is not as important a factor. Finally, the strength of the cation-anion interaction

20 is stronger for calcium than for any of the other systems. This is supported by our radial

21 distribution function analysis of the cation-anion distances (Figure S5). These distances are far

22 greater for the other systems meaning that the first solvation shell for other cations is dominated

23 by the carbonate solvents whereas there is far more balance in the case of the calcium ions.

24 Together these factors help explain the structural complexity observed for calcium compared

25 to the other ions.

26 Both the number of carbonate solvents and their spatial arrangement affect the 27 interaction mode and behavior of the $\left[\mathrm{BF}_{4}\right]^{-}$anions. As shown in Table 1, the carbonate: anion 28 ratio is higher for complexes with mono-coordinated $\left[\mathrm{BF}_{4}\right]^{-}$than for those in which the $\left[\mathrm{BF}_{4}\right]^{-}$ 29 anions form a bifurcated interaction. Therefore, $\left[\mathrm{BF}_{4}\right]^{-}$anions tend to mono-coordinate to the $30 \mathrm{Ca}^{2+}$ ion due to a lack of space in the first coordination shell. This leads to a weaker interaction 31 for these mono-coordinated $\left[\mathrm{BF}_{4}\right]^{-}$anions than for the bi-coordinated $\left[\mathrm{BF}_{4}\right]^{-}$anions, as is 
1 suggested by the smaller values for the sums of electron density $\left(\sum \rho(r)\right)$ at the bond critical

2 points (BCPs) for the mono- vs bi-coordinated systems (Table S1).

3 The carbonate solvents interact with the $\mathrm{Ca}^{2+}$ ion through the lone pair electrons of their

4 carbonyl groups $\left(\mathrm{Ca}^{2+} \bullet \bullet O\right.$ interactions $)$ and the $\left[\mathrm{BF}_{4}\right]^{-}$anions are coordinated to the $\mathrm{Ca}^{2+}$ ion

5 by the lone pair electrons of their fluorine atoms $\left(\mathrm{Ca}^{2+} \bullet \bullet \mathrm{F}\right.$ interactions $)$. The average distance

6 between the calcium and the coordinating atoms range between $2.30-2.50 \AA$, and depend on

7 the type of carbonate solvent (cyclic vs acyclic) as well as on the number and orientation of

8 the coordinating solvent and $\left[\mathrm{BF}_{4}\right]^{-}$molecules surrounding the $\mathrm{Ca}^{2+}$ ion. Shorter carbonyl-

$9 \mathrm{Ca}^{2+}$ distances correlate with more favorable $\Delta \mathrm{H}_{(\mathrm{sol})}$ and $\Delta \mathrm{G}_{(\text {sol) }}$, with a small offsetting penalty

10 in $\Delta \mathrm{S}_{(\mathrm{sol})}$. As shown in Figure $1 \mathrm{~b}$, the $\Delta \mathrm{G}_{(\mathrm{sol})}$ values of the $\mathrm{Ca}^{2+}$-ion complexes have good

11 correlation with the interaction strength of carbonyl groups in the first solvation shell. The

12 greater the $\Delta \mathrm{G}_{(\mathrm{sol})}$ values, the stronger is the interaction of oxygen atoms of the carbonyl groups

13 with the $\mathrm{Ca}^{2+}$ ion in the first solvation shell. The least favored systems note the inverse

14 relationship, with less favorable enthalpy and Gibbs free energy terms, but lesser penalties to

15 entropy. Closer association of the carbonyl electrolytes to the calcium core improves solvation.

16 The tetrafluoroborate plays a lesser role in determining the free energy of solvation as there is

17 no clear correlation between these distances and the thermodynamic parameters.

19 Table 1. The ratio of carbonate: anion, average $\mathrm{Ca}^{2+} \bullet \bullet \mathrm{O}$ and $\mathrm{Ca}^{2+} \bullet \bullet \mathrm{F}$ bond lengths and 20 thermochemical properties of the $\mathrm{Ca}^{2+} \bullet \bullet$ carbonate solvent complexes.

21

\begin{tabular}{|c|c|c|c|c|c|c|c|}
\hline Structures & Coordinated species & $\mathrm{Ca}^{2+}-\mathrm{O}(\AA)$ & $\mathrm{Ca}^{2+}-\mathrm{F}(\AA)$ & ${ }^{\mathrm{a}} \Delta \mathrm{E}_{\mathrm{b}(\mathrm{kcal} / \mathrm{mol})}$ & $\Delta \mathrm{H}_{(\mathrm{sol})(\mathrm{kcal} / \mathrm{mol})}$ & $\Delta \mathrm{S}_{(\mathrm{sol})(\mathrm{cal} / \mathrm{mol} . \mathrm{K})}$ & $\Delta \mathrm{G}_{(\text {(sol)(kcal/mol) }}$ \\
\hline $\mathrm{Ca}^{2+}(\mathrm{EC})$ & $8 \mathrm{EC}: 1 \mathrm{BF}_{4}^{-}$ & 2.40 & 2.32 & -498.97 & -520.98 & -366.27 & -411.77 \\
\hline $\mathrm{Ca}^{2+}(\mathrm{VC})$ & $8 \mathrm{VC}: 1 \mathrm{BF}_{4}^{-}$ & 2.48 & 2.37 & -467.32 & -486.24 & -340.94 & -384.59 \\
\hline $\mathrm{Ca}^{2+}(\mathrm{PC})$ & $8 \mathrm{PC}: 1 \mathrm{BF}_{4}^{-}$ & 2.52 & 2.31 & -482.93 & -503.44 & -353.87 & -397.93 \\
\hline $\mathrm{Ca}^{2+}(\mathrm{BC})$ & $6 \mathrm{BC}: 2 \mathrm{BF}_{4}^{-}$ & 2.41 & 2.39 & -538.43 & -556.14 & -316.72 & -461.71 \\
\hline $\mathrm{Ca}^{2+}(\mathrm{DMC})$ & $6 \mathrm{DMC}: 2 \mathrm{BF}_{4}^{-}$ & 2.45 & 2.41 & -531.28 & -548.19 & -342.37 & -446.11 \\
\hline $\mathrm{Ca}^{2+}(\mathrm{EMC})$ & $4 \mathrm{EMC}^{2} 2 \mathrm{BF}_{4}^{-}$ & 2.36 & 2.38 & -524.60 & -535.80 & -244.00 & -463.05 \\
\hline $\mathrm{Ca}^{2+}(\mathrm{DEC})$ & 4DEC:2BF4 ${ }^{-}$ & 2.38 & 2.41 & -520.77 & -533.57 & -246.79 & -459.99 \\
\hline $\mathrm{Ca}^{2+}(\mathrm{EC}: \mathrm{PC})$ & $5 \mathrm{EC}: 3 \mathrm{PC}: 1 \mathrm{BF}_{4}^{-}$ & 2.42 & 2.38 & -483.11 & -504.35 & -359.06 & -397.30 \\
\hline $\mathrm{Ca}^{2+}(\mathrm{EC}: \mathrm{DMC})$ & $7 \mathrm{EC}: 1 \mathrm{DMC}: 1 \mathrm{BF}_{4}^{-}$ & 2.43 & 2.36 & -489.75 & -509.49 & -357.69 & -402.84 \\
\hline $\mathrm{Ca}^{2+}(\mathrm{EC}: \mathrm{EMC})$ & $4 \mathrm{EC}: 2 \mathrm{EMC}: 2 \mathrm{BF}_{4}^{-}$ & 2.47 & 2.43 & -539.39 & -556.63 & -314.79 & -462.77 \\
\hline $\mathrm{Ca}^{2+}(\mathrm{EC}: \mathrm{DEC})$ & 4EC:2DEC:2BF ${ }^{-}$ & 2.43 & 2.36 & -550.86 & -569.93 & -327.85 & -472.18 \\
\hline
\end{tabular}

${ }^{\mathrm{a}}$ These 2eported binding energies $\left(\Delta \mathrm{E}_{\mathrm{b}}\right)$ have been corrected by BSSE. 
The thermochemical properties of $\mathrm{Ca}^{2+} \bullet \bullet$ carbonate solvent complexes, including 2 binding energy $\left(\Delta \mathrm{E}_{\mathrm{b}}\right)$, enthalpy, entropy, and free energy of solvation are summarized in Table 1. The binding energy $\left(\Delta \mathrm{E}_{\mathrm{b}}\right)$ is indicative of the compatibility of the $\mathrm{Ca}^{2+}$ ion with the various

4 carbonates. The binding energy is strongly dependent on the type of carbonate solvent, the 5 number of carbonate solvents, the number and nature of the $\left[\mathrm{BF}_{4}\right]^{-}$coordination, and the 6 coordination mode of the $\mathrm{Ca}^{2+}$ ion. ${ }^{32}$ In all $\mathrm{Ca}^{2+} \bullet \bullet$ carbonate solvent complexes, both the 7 carbonate solvents and $\left[\mathrm{BF}_{4}\right]^{-}$anions are coordinated to the $\mathrm{Ca}^{2+}$ ion through the oxygen atoms 8 of carbonyl groups and the fluorine atoms, respectively. As mentioned above, the arrangement 9 of $\left[\mathrm{BF}_{4}\right]^{-}$anions and the strength of their interaction with the $\mathrm{Ca}^{2+}$ ion depend on the number of carbonate solvents in the first coordination shell. An increase in the number of $\left[\mathrm{BF}_{4}\right]^{-}$anions

11 from one to two in the $\mathrm{Ca}^{2+} \bullet \bullet$ carbonate solvent complexes, irrespective of the behaviour of 12 the carbonate solvents, enhances the $\sum \rho(\mathrm{r})$ values at the $\mathrm{BCPs}$ of $\mathrm{Ca}^{2+} \bullet \bullet \mathrm{F}$ interactions and thus 13 increases the binding energy values, possibly due to minimizing the charge on the complex. 14 For example the EC:DEC system, with 2 counterions and 6 solvent molecules, is almost 100 $15 \mathrm{kcal} / \mathrm{mol}$ lower in energy than the VC-solvated system. These calculations imply that the highest binding energies are seen for the butylene carbonate $(\mathrm{BC},-538.43 \mathrm{kcal} / \mathrm{mol})$ and the equimolar mixture of ethylene carbonate and diethyl carbonate (EC:DEC, $-550.86 \mathrm{kcal} / \mathrm{mol})$. Despite the significant differences in binding energy, all systems are enthalpically highly favorable. carbonate solvents and $\left[\mathrm{BF}_{4}\right]^{-}$anions and leads to the negative values of $\Delta \mathrm{S}_{(\mathrm{sol})}$. However, the enthalpy term dominates the interaction ensuring these are favorable processes. ${ }^{30-33}$ In addition, all calculated $\Delta \mathrm{G}_{(\text {sol })}$ values are negative and show that these systems are both exothermic and exergonic. ${ }^{30-33}$ In general, for all systems, the greater the enthalpy term, the greater is the magnitude of the free energy of solvation.

Ranking the carbonate systems based on the calculated free energy of solvation $\left(\Delta \mathrm{G}_{(\mathrm{sol})}\right.$ rather than binding energy, $\left.\Delta \mathrm{E}_{\mathrm{b}}\right)$ of the $\mathrm{Ca}^{2+}$ ion provides the following order EMC> $\mathrm{BC}>\mathrm{DEC}>\mathrm{DMC}>\mathrm{EC}>\mathrm{PC}>\mathrm{VC}$ for the pure carbonate solvents and $\mathrm{EC}: \mathrm{DEC}>\mathrm{EC}: \mathrm{EMC}>$ $\mathrm{EC}: \mathrm{DMC}>\mathrm{EC}: \mathrm{PC}$ for the binary mixtures of carbonate solvents. According to these orders, the EMC and EC:DEC solvents are the best electrolytes among pure and binary mixtures of carbonate solvents for the $\mathrm{Ca}^{2+}$-ion batteries, respectively. The latter result is particularly 
1 interesting as neither solvent on its own is particularly suitable, but the combination appears to

2 allow each solvent to compensate for the deficiencies of the other.

The calculated free energies of solvation of the $\mathrm{Ca}^{2+}$ ion are compared with those of

$4 \mathrm{Li}^{+}, \mathrm{Na}^{+}$and $\mathrm{Mg}^{2+}$ ions in Figure 2. ${ }^{4,32,33} \mathrm{~A}$ larger free energy of solvation correlates to higher 5 solubility. The comparison illustrates the clear trend in solubility: $\Delta \mathrm{G}_{(\mathrm{sol})}\left(\mathrm{Ca}^{2+}\right)>\Delta \mathrm{G}_{(\mathrm{sol})}\left(\mathrm{Mg}^{2+}\right)$

$6>\Delta \mathrm{G}_{(\mathrm{sol})}\left(\mathrm{Li}^{+}\right)>\Delta \mathrm{G}_{(\mathrm{sol})}\left(\mathrm{Na}^{+}\right)$. As the enthalpy term dominates, this is the same trend that is 7 observed for the free energy of binding as well. Within this series, the divalent ions, $\mathrm{Mg}^{2+}$ and $8 \mathrm{Ca}^{2+}$ are notably more soluble than monovalent $\mathrm{Li}^{+}$and $\mathrm{Na}^{+}$. This result is in good agreement 9 with the results reported by Okoshi and coworkers who determined that the $\mathrm{Mg}^{2+}$ ion has a 10 remarkably larger de-solvation energy in electrolyte solvents than $\mathrm{Li}^{+}$and $\mathrm{Na}^{+}$ions because of 11 its double positive charge. ${ }^{67}$ Similarly, Ponrouch et al. experimentally determined that 12 carbonate electrolyte solutions of $\mathrm{Mg}^{2+}$ and $\mathrm{Ca}^{2+}$ exhibit significantly stronger cation-carbonate 13 interactions than solutions of $\mathrm{Li}^{+}$and $\mathrm{Na}^{+}{ }^{66}$ This means that the divalent cations will have 14 lower mobility in the electrolyte solution, and this will have a detrimental impact on their 15 efficiency for battery discharge rates.

A key feature to achieve the required long cycle life of metal-ion batteries is the selection of the proper electrolyte system able to readily both solvate (to discharge the battery) and desolvate (to charge the battery) the ion. ${ }^{18}$ Calcium tetrafluoroborate is readily solvated by all of carbonate solvents as indicated by the highly exothermic and exergonic energies calculated above. Although, this means that desolvation is energetically expensive, this need not be the case. The desolvation process at the solid electrolyte interphase can be facilitated by increasing the temperature of the system employing anions with a delocalized negative charge, such as bis(trifluoromethylsulfonyl)imide (TFSI), modifying the presence of additives, and redesigning electrodes to have a larger free energy of interaction with the ion. ${ }^{18,66}$ These interventions will likely prove necessary for calcium-based batteries, as they clearly have a much higher energy of desolvation than the other three cations. These analyses will form the 27 basis of a future study.

This observation, the expected difficulty of desolvation, is in good agreement with the results of Ponrouch et al. who required an elevated temperature $\left(100{ }^{\circ} \mathrm{C}\right)$ to demonstrate 30 feasible calcium plating using carbonate electrolytes. ${ }^{18}$ A clear priority for the future 
1 development of $\mathrm{Ca}$-ion batteries will be to reduce the operating temperature required for

2 effective desolvation as much as possible.

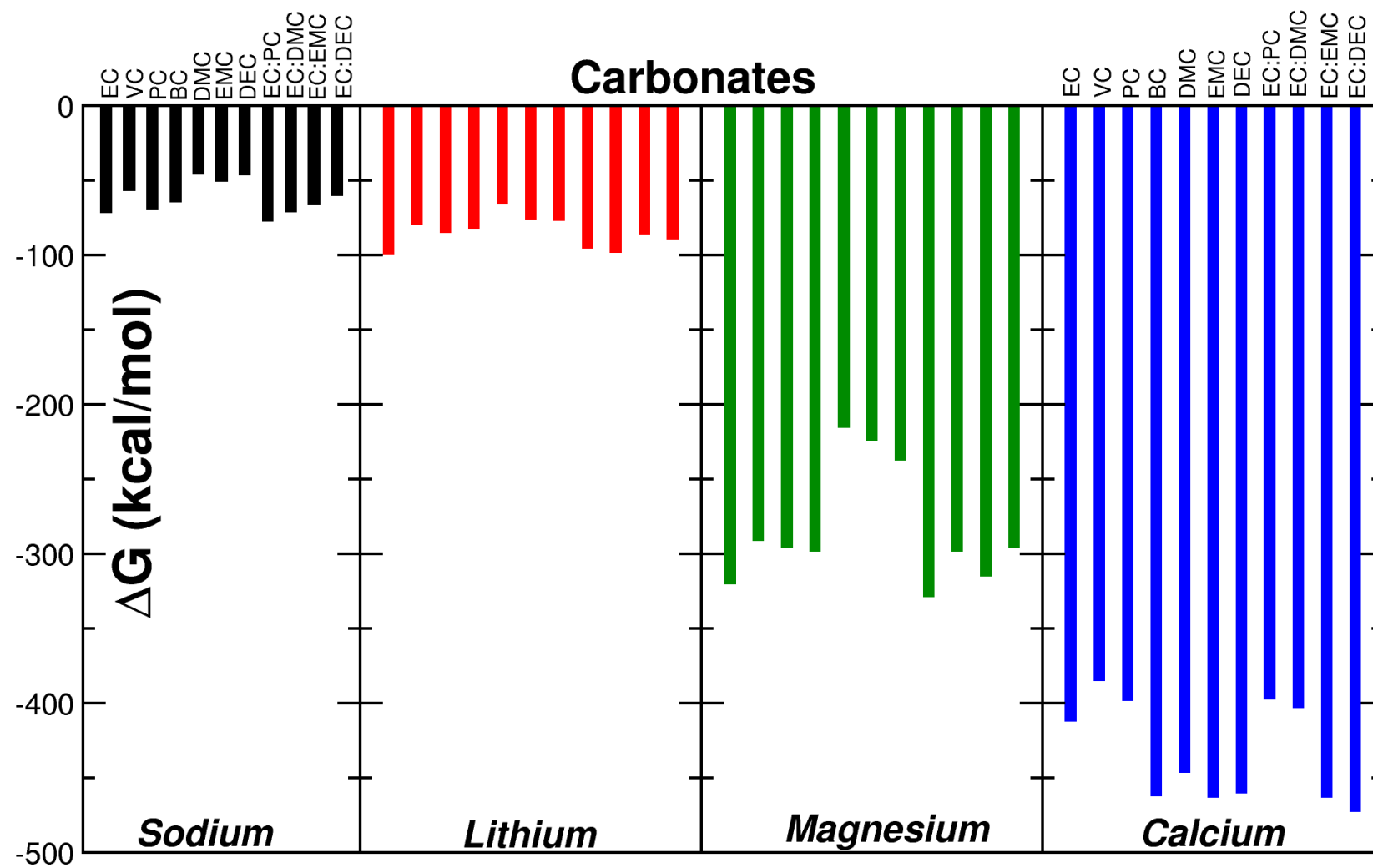

Figure 2. Comparison of the free energy of solvation of $\mathrm{Li}^{+}, \mathrm{Na}^{+}, \mathrm{Mg}^{2+}$ and $\mathrm{Ca}^{2+}$ ions in various acyclic and cyclic carbonates and their binary mixtures as calculated at the M06-2X/6$311++G(d, p)$ level of theory, labels are provided for the first series only for clarity. The free energy of solvation of $\mathrm{Li}^{+}, \mathrm{Na}^{+}$and $\mathrm{Mg}^{2+}$ ions has been reproduced from our previous studies for comparison purposes only. ${ }^{30,32,33}$

To gain further insight into the degree of charge transfer between the solvated $\mathrm{Ca}^{2+}$ ions and their coordinating solvents and $\left[\mathrm{BF}_{4}\right]^{-}$anions, NBO analysis was carried out at the M06$2 \mathrm{X} / 6-311++\mathrm{G}(\mathrm{d}, \mathrm{p})$ level of theory. The amount of charge transfer $\left(\Delta \mathrm{qCa}^{2+}\right)$ in each complex is defined as the difference between the charge of an isolated $\mathrm{Ca}^{2+}$ ion and the charge of the $\mathrm{Ca}^{2+}$ ion in the corresponding complexes $\left(\Delta \mathrm{q}_{\mathrm{Ca}}{ }^{2+}=\mathrm{qCa}^{2+}{ }_{\text {(Isolated) }}-\mathrm{qCa}^{2+}\right.$ (Complexed) $)$. The charge transfer occurs from carbonate solvents and $\left[\mathrm{BF}_{4}\right]^{-}$anions to the $\mathrm{Ca}^{2+}$ ion through $\mathrm{Ca}^{2+} \cdots \mathrm{O}$ and $\mathrm{Ca}^{2+} \cdots \mathrm{F}$ interactions. The highest calculated charge transfers for pure carbonate complexes 
1 and binary mixture complexes were determined for $\mathrm{Ca}^{2+}(\mathrm{VC})(0.6488 \mathrm{e})$ and $\mathrm{Ca}^{2+}(\mathrm{EC}: \mathrm{DEC})$

2 (0.6162e), respectively.

An NBO analysis to evaluate the donor-acceptor interactions $\left(\mathrm{Ca}^{2+} \cdot \boldsymbol{\bullet}^{\mathrm{O}}\right.$ and $\left.\mathrm{Ca}^{2+} \cdot \cdots \mathrm{F}\right)$

4 showed that they are present mostly between the lone pairs of oxygen atoms $\left(\operatorname{lp}_{(0)}\right)$ in the

5 carbonyl groups and the lone pairs of the fluorine atoms $\left(\mathrm{lp}_{(\mathrm{F})}\right)$ in the $\left[\mathrm{BF}_{4}\right]^{-}$anions with the unoccupied $1 p^{*}$ orbital of the $\mathrm{Ca}^{2+}$ ion $\left(\mathrm{lp}_{(\mathrm{O})} \rightarrow \mathrm{lp}^{*}{ }_{(\mathrm{Ca}}{ }^{2+}\right)$ and $\left.\mathrm{lp}_{(\mathrm{F})} \rightarrow \mathrm{lp}_{\left(\mathrm{Ca}^{2+}\right)}\right)^{2+}$. The total values of

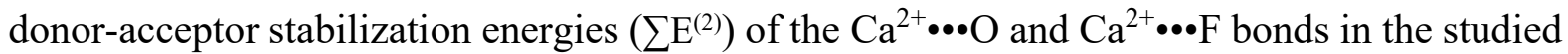
complexes are listed in Table S1.

The highest value of $\sum \mathrm{E}^{(2)}$ is observed for $\mathrm{Ca}^{2+}(\mathrm{VC})(423.23 \mathrm{kcal} / \mathrm{mol})$. To evaluate the bond strength of $\mathrm{Ca}^{2+}$ with carbonate solvents and $\left[\mathrm{BF}_{4}\right]^{-}$anions, the Wiberg bond index was also calculated for all complexes. The sum of the $\mathrm{Ca}^{2+} \bullet \bullet \mathrm{O}$ and $\mathrm{Ca}^{2+} \bullet \bullet \mathrm{F}$ Wiberg bond indices

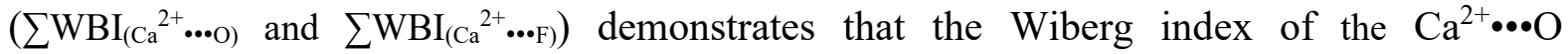
interactions is greater than that of the $\mathrm{Ca}^{2+} \bullet \bullet \mathrm{F}$ interactions. This means that the $\mathrm{Ca}^{2+} \bullet \bullet \mathrm{O}$ are more important for delocalizing the charge on calcium than the anionic counterion. The QTAIM analysis of these interactions also supports this contention (Tables S1 and S2). The sum of electron density $\left(\sum \rho(\mathrm{r})\right)$ at the bond critical points (BCPs) of the $\mathrm{Ca}^{2+} \bullet \bullet \mathrm{O}$ interactions is higher than that at the BCP of the $\left(\mathrm{Ca}^{2+} \bullet \bullet \mathrm{F}\right)$ bonds. Both of these calculations, independent and complementary methods to measure the relative importance of interactions, indicate that the $\mathrm{Ca}^{2+}$-carbonate interactions are stronger than those between $\mathrm{Ca}^{2+}$ and $\left[\mathrm{BF}_{4}\right]^{-}$. This same conclusion can be reached by examining the HOMO and LUMOs of these systems (Figures S8 and S9).

The interaction of the $\mathrm{Ca}^{2+}$ ion with both the carbonate solvents and $\left[\mathrm{BF}_{4}\right]^{-}$anions can be further probed by analyzing their infrared (IR) spectra (Figure S10). Vibrational analysis on the optimized structures of isolated carbonate solvents and their complexes with $\mathrm{Ca}^{2+}$ ion shows that the $\mathrm{C}=\mathrm{O}$ stretching frequencies in carbonate solvents and their binary mixtures can be affected by the presence of a $\mathrm{Ca}^{2+}$ ion. The greatest changes in vibrational frequencies between the isolated and complexed systems are related to the frequencies arising from the carbonyl groups. These stretching frequencies become red-shifted after binding with the $\mathrm{Ca}^{2+}$ ion, indicating that $\mathrm{C}=\mathrm{O}$ bonds are weakened due to the redistribution of the electron density 30 around the oxygen atoms that arises upon complexation. The changes in the vibrational 31 frequencies of $\mathrm{C}=\mathrm{O}$ groups are in line with the corresponding bond lengths and electron 
1 densities observed for the $\mathrm{C}=\mathrm{O}$ groups. These observations are in good agreement with the 2 results reported in the literature. ${ }^{30,32,33,68,69}$

In order to understand the nature of the interactions between the $\mathrm{Ca}^{2+}$ ion and the

4 ligands, the values of the electron density Laplacian $\left(\nabla^{2} \rho(\mathrm{r})\right)$, the kinetic energy density $(\mathrm{G}(\mathrm{r}))$, 5 the potential energy density $(\mathrm{V}(\mathrm{r}))$ and the total energy density $(\mathrm{H}(\mathrm{r}))$ at the BCPs of $\mathrm{Ca}^{2+} \bullet \bullet O$ 6 and $\mathrm{Ca}^{2+} \cdot \bullet \mathrm{F}$ bonds were also determined (Table S2). From the strongly positive values of $7 \quad \nabla^{2} \rho(\mathrm{r})$ and $\mathrm{H}(\mathrm{r})$ at the BCPs formed between $\mathrm{O}$ atoms of carbonate solvents and $\mathrm{Ca}^{2+}$ ion $8\left(\mathrm{Ca}^{2+} \bullet \mathrm{O}\right)$ as well as between $\mathrm{F}$ atoms of $\left[\mathrm{BF}_{4}\right]^{-}$anions and $\mathrm{Ca}^{2+}$ ion $\left(\mathrm{Ca}^{2+} \bullet \cdot \mathrm{F}\right)$, it can be 9 concluded that the $\mathrm{Ca}^{2+} \bullet \cdot \mathrm{O}$ and $\mathrm{Ca}^{2+} \bullet \bullet \mathrm{F}$ interactions are classified as clear electrostatic 10 interactions. The electrostatic nature of the $\mathrm{Ca}^{2+} \bullet \bullet \mathrm{O}$ and $\mathrm{Ca}^{2} \bullet \bullet F$ interactions was also revealed 11 by noncovalent interaction (NCI) plots which display a scatter plot of the magnitude of the 12 electron density represented by the second eigenvalue of the density Hessian, $\operatorname{sign}\left(\lambda_{2}\right) \rho$, at 13 points with a given low-reduced density gradient $s(r)$ value (Figure 3$){ }^{70}$ These plots refine the 14 analysis of the type and strength of noncovalent interactions. The sign of $\lambda_{2}$ and the electron density $(\rho)$ value determine the type and strength of noncovalent interactions, respectively. A negative sign of $\lambda_{2}$ is indicative of strong attractive interactions (i.e. electrostatic interactions,

17 hydrogen bond interactions and halogen bond interactions) whereas a positive value is typical of strong repulsive interactions, including steric effects. Values near zero indicate van der Waals interactions. In the plots, the strength of these noncovalent interactions at a given reduced density gradient (RDG) isosurface is represented using a colorimetric scale. Blue, green and red indicate strong attraction, weak Van der Waals interactions, and strong repulsive interactions respectively. Figure 3 illustrates a scatter plot of RDG versus $\operatorname{sign}\left(\lambda_{2}\right) \rho$ and a 3D representation of the reduced density gradient ( $\mathrm{RDG}, 0.5$ a.u.) for the $\mathrm{Ca}^{2+}(\mathrm{EC})$ complex superimposed on the molecular structure. The surfaces calculated between both the carbonyls of the carbonate solvents and the fluorides of the trifluoroborates with the $\mathrm{Ca}^{2+}$ core are bright blue indicating the presence of strong electrostatic attractive interactions. This observation is in good agreement with the results obtained from QTAIM analysis. On the other hand, the green regions between carbonate solvents and the $\left[\mathrm{BF}_{4}\right]^{-}$anions show that the presence of Van der Waals interactions organize the co-ordination sphere. Similar plots are provided for the other complexes as Figure S11. 


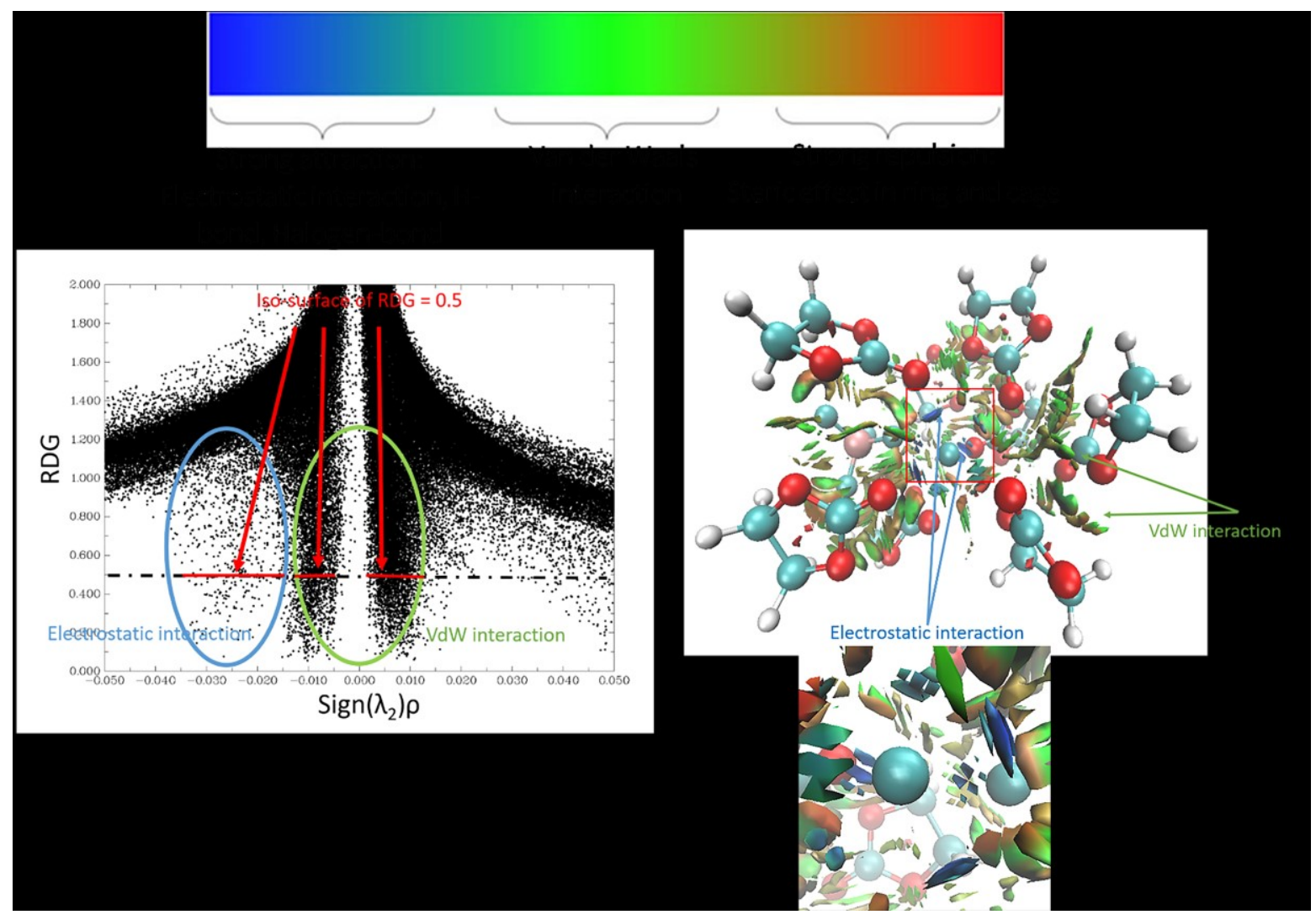

1

2

3

4

Figure 3. The scatter plot of reduced density gradient (RDG) versus $\operatorname{sign}\left(\lambda_{2}\right) \rho$ and $3 \mathrm{D}$ graphic of reduced density gradient (RDG, 0.5 a.u.) for the $\mathrm{Ca}^{2+}(\mathrm{EC})$ complex. Blue, green, and red colors indicate the strong attractive, weak vdW, and strong repulsion interactions respectively. An insert provides a zoom of the interactions immediately around the calcium center. Similar plots for other systems are provided as Figure S11.

Ion complexation will change the electronic structure of the components. To analyze this effect, the HOMO and LUMO orbital energies and the HOMO-LUMO energy gap ( $\mathrm{E}_{\mathrm{g}}$ ) were calculated for the isolated carbonate solvents and the $\mathrm{Ca}^{2+}$-ion complexes (Table $\mathrm{S} 3$, and Figure S8). For two cases, EMC, and 1:1 EC:DEC, the HOMO-1 and LUMO+1 orbitals were also modeled (Figure S9). In all complexes, the HOMO and LUMO (and HOMO-1 and LUMO+1) are located primarily on the electrolyte molecules. The HOMO density is localized to carbonyl functionalities oriented in close association with the calcium center. The LUMO densities are located on the most distal electrolyte molecules. The tetrafluoroborate functionalities have a small contribution to these FMOs, and there is no observable density on 
1 the calcium center for any of the systems. The degree of change in the energies of the frontier 2 molecular orbitals (FMOs) depends on the solvent. DEC has almost no decrease in the HOMO 3 energy upon complexation, while $\mathrm{EC}$ and $\mathrm{VC}$ show a $2 \mathrm{eV}$ decrease and $\mathrm{BC}$ demonstrates a 4 slight increase upon complexation. In contrast, the energies of the LUMOs universally become 5 more negative upon complexation. These shifts lead to changes in the HOMO-LUMO energy 6 gap of the carbonate solvents when coordinated. The HOMO-LUMO energy gap of un7 coordinated EC, VC, PC, BC, DMC, EMC, and DEC solvents falls within the range of 8.58 to $8 \quad 10.26 \mathrm{eV}$. This energy gap decreases upon interaction with the $\mathrm{Ca}^{2+}$ ion (Figure S12). The 9 HOMO-LUMO energy gap of the mixed solvent systems (PC, EMC and DEC with EC) is 10 generally smaller than that found in the one-solvent complexes with the exception of the 11 EC:DMC. We propose that this arises because of the reorganization and subsequent weakening 12 of the interaction between these acyclic carbonates and the tetrafluoroborate with the calcium 13 centre upon exposure to the cyclic EC. Calculating the electron density at the bond critical 14 points shows that the interaction between the carbonyl oxygen of the acyclic carbonates and the calcium ion decreases by between two and four-fold in the mixed system compared to the pure carbonate system (Table S4). We see a similar decrease in the electron density at the bond critical point for the anion-calcium interaction. This is always offset by the addition of a new interaction with EC, which is always stronger than that with the acyclic carbonate in the mixed systems, but is still lower than that of the acyclic carbonate alone. Except in the case of DMC where the larger number of ECs in the cluster leads to a higher electron density at the bond critical point. One of the reasons for this difference in behaviour is that different numbers of EC molecules displace the acyclic carbonates in the complexes. This is especially the case for DMC where a large number of EC molecules are present in the first solvation shell, especially compared with the other mixtures (7EC:1DMC:1BF 4 vs $5 \mathrm{EC}: 3 \mathrm{PC}_{1} 1 \mathrm{BF}_{4}^{-}, 4 \mathrm{EC}: 2 \mathrm{EMC}^{-2} \mathrm{BF}_{4}^{-}$, 4EC:2DEC:2 $2 \mathrm{BF}_{4}^{-}$, Table 1). Hence, it seems that the stronger interaction of $\mathrm{EC}$ with $\mathrm{Ca}^{2+}$ compared to any of PC, DMC, EMC, DEC or $\mathrm{BF}_{4}^{-}$highlights the ability of the very small EC molecule to perturb charge distribution and the strength of the interactions, which in turn affects charge transfer as manifested in the HOMO/LUMO energies. This stronger interaction raises the HOMO-LUMO energy gap relative to the pure solvent mixture for DMC alone. The weaker interactions lower the HOMO-LUMO energy gaps of the other solvents in a mixture with EC relative to the solvents alone. 
The shifting of the frontier molecular orbital energies upon complexation affects the

2 oxidative and reductive potentials of the related systems facilitating solvation, charge transfer, and modifying the polarity of the first solvation shell. ${ }^{71}$

The shifting of the HOMO and LUMO orbital energies of the carbonate solvents upon 5 ion complexation also affects the global molecular descriptors of the carbonate solvents, 6 including their electronic chemical potential $(\mu)$, chemical hardness $(\eta)$, global softness (S) and 7 electrophilicity index ( $\omega)$ (Table S3 and Figure S12). The $\mu$ and $\eta$ values of carbonate solvents 8 decreases upon ion complexation. In addition, these values are also lower when EC is used as 9 a co-solvent to the PC, DMC, EMC and DEC solvents, than when those four carbonates are used alone. A low HOMO-LUMO energy gap indicates less stability and a higher degree of reactivity for a chemical system. A soft molecule with a small HOMO-LUMO energy gap will be more polarizable than a hard molecule with a large HOMO-LUMO energy gap. Based on this criterion, the $\mathrm{Ca}^{2+}$-ion complexes are predicted to be softer (lower $\eta$ value) and have higher reactivity than the carbonate solvents alone. The electrophilic nature of carbonate solvents is evaluated using the electrophilicity index $(\omega)$, which measures the stabilization in energy when the carbonate solvents and their complexes gain an additional electronic charge from the environment. The electrophilic nature of carbonate solvents increases through complexation with $\mathrm{Ca}^{2+}$ ion and through the addition of EC as a co-solvent (Figure S12). Curiously, these various parameters, the energies of the HOMO and LUMO and the values of $\mu$ and $\omega$, appear to be correlated with the free energy of solvation (Figures 4 and 5).
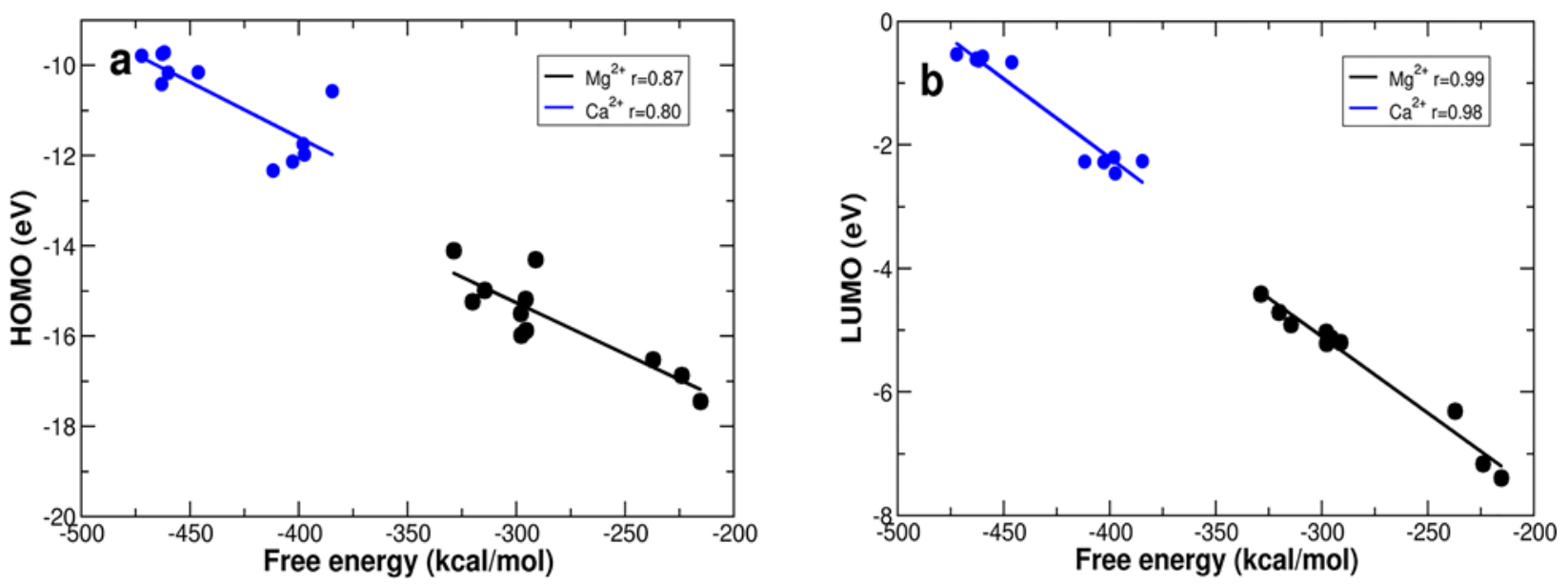
Figure 4. Relationship between (a) Free energies of solvation and HOMO orbital energies and (b) Free energies of solvation and LUMO orbital energies of the $\mathrm{Mg}^{2+}$ and $\mathrm{Ca}^{2+}$-ion complexes. The correlation coefficient between the HOMO/LUMO orbital energies and the free energy of $\mathrm{Ca}^{2+} \cdot . \cdot$ carbonate solvent complex is 0.80 and 0.98 respectively. The data related to $\mathrm{Mg}^{2+}$-ion complexes has been taken from our previous study. ${ }^{33}$

We observe a very strong correlation between the free energy of solvation and the HOMO/LUMO orbital energies of both the divalent $\mathrm{Mg}^{2+}(\mathrm{r}=0.87$ and 0.99 , respectively) and $\mathrm{Ca}^{2+}$-ion ( $\mathrm{r}=0.80$ and 0.98 , respectively). This makes intuitive sense, as the energy of solvation dominates the energies of these systems, and solvation for these systems is driven by carbonylcalcium interactions; however, the correlation is remarkable considering the impact that other factors could play, and the reason for the even better correlation with the energy of the LUMO is not clear. This is especially the case as the density in the LUMO is located asymmetrically on the periphery of the solvated complex. This same relationship is not apparent for the monovalent sodium and lithium ions where the free energy of solvation is largely independent of the nature of the carbonate solvent (data not shown).

Similarly, Figure 5 plots $\mu$ and $\omega$ for the carbonate complexes with all for cations as a function of the free energy of solvation. The $\mu$ values of the $\mathrm{Mg}^{2+}$ and $\mathrm{Ca}^{2+}$-ion complexes increase proportionally to the free energy of solvation, while the $\omega$ values for these complexes decrease. This is clearly not the case for the $\mathrm{Li}^{+}$and $\mathrm{Na}^{+}$-ion complexes (calculated from our previously obtained data), ${ }^{30,32}$ where no such correlation is observed. A correlation would be expected as these parameters would have a strong effect on the charge-discharging mechanism of the carbonate electrolytes. The lack of a correlation with the monovalent ions is curious. Finally, these results suggest that the HOMO-LUMO gap might be a useful surrogate for battery efficiency when divalent ions are considered. This could form the basis for the computational screening of potential electrolytes to identify the most promising ratios and mixtures for maximizing the solubility, and charge density, of future $\mathrm{Ca}$-ion battery systems. 

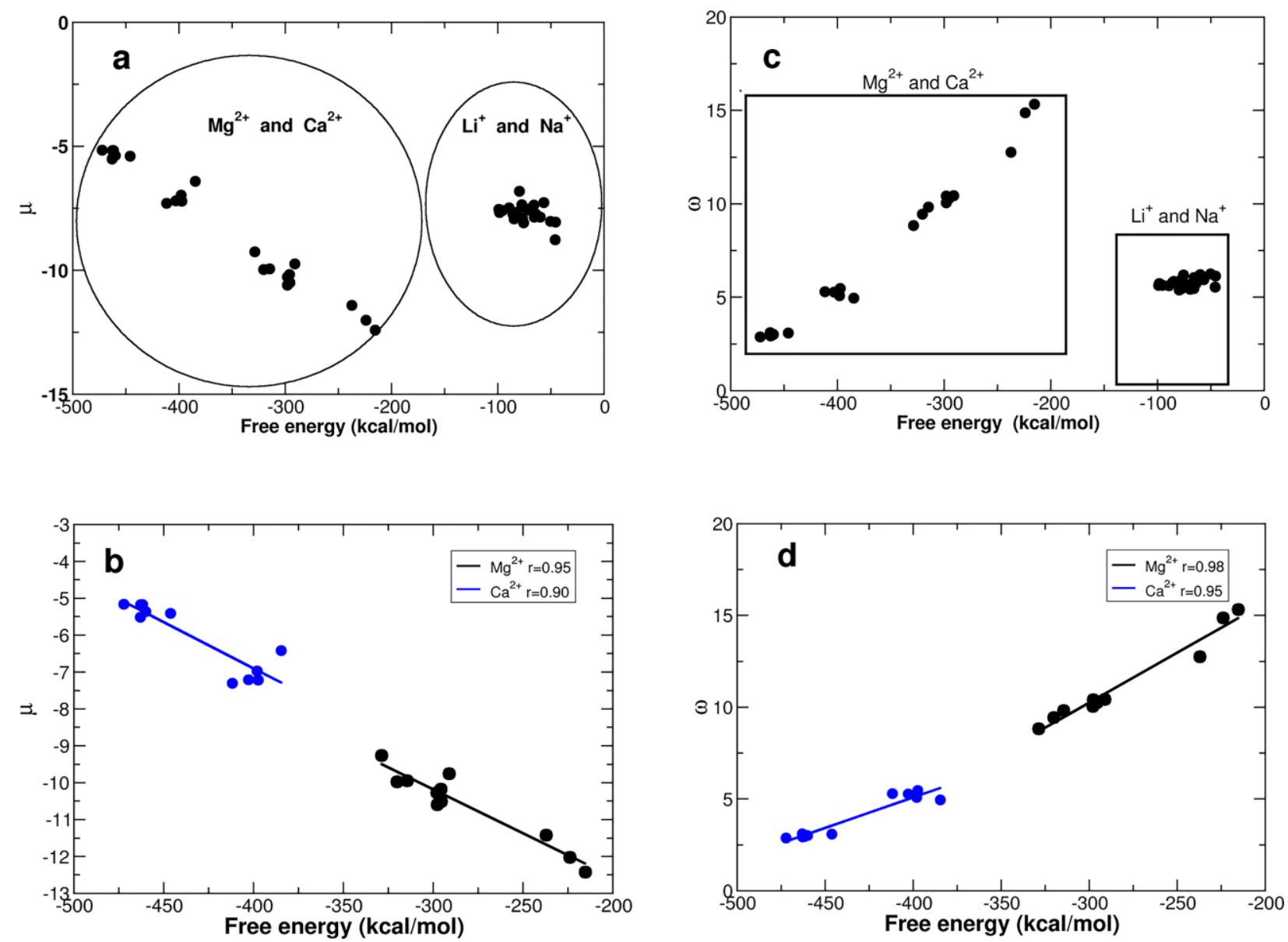

1 Figure 5. Relationship between free energy of solvation and (a,b) electronic chemical potential

2 ( $\mu$ ) and (c,d) electrophilicity index $(\omega)$ of the $\mathrm{Li}^{+}, \mathrm{Na}^{+}, \mathrm{Mg}^{2+}$ and $\mathrm{Ca}^{2+}$-ion complexes. b) the

3 correlation between electronic chemical potential $(\mu)$ and free energy of solvation for $\mathrm{Mg}^{2+}$ and

$4 \mathrm{Ca}^{2+}$ are 0.95 and 0.90 , respectively. $\left.\mathrm{d}\right)$ the correlation between electrophilicity index $(\omega)$ and

5 free energy of solvation for $\mathrm{Mg}^{2+}$ and $\mathrm{Ca}^{2+}$ are 0.98 and 0.95 , respectively. No such correlation

6 exists for the mono-valent ions - Lithium or Sodium.

7

\section{3. Conclusions}

9 In this study, the solubility and solvation behavior of $\mathrm{Ca}^{2+}$ ion in pure carbonate solvents 10 (EC, VC, PC, BC, DMC, EMC and DEC) and four binary mixtures of carbonates (EC:PC, 11 EC:DMC, EC:EMC, and EC:DEC) are investigated using combined molecular dynamics 12 (MD) simulations and density functional theory (DFT) calculations. These calculations 13 identify pure EMC and the binary mixture EC:DEC are the best electrolytes for potential $\mathrm{Ca}^{2+}$ 14 ion batteries. 
A comparison between the free energy of solvation of $\mathrm{Ca}^{2+}$ ion in the carbonate solvents

2 with our previously reported $\mathrm{Li}^{+}, \mathrm{Na}^{+}$and $\mathrm{Mg}^{2+}$ ions, indicates that calcium is far more soluble 3 than any of the other cations.

$4 \quad \mathrm{The}^{2+}$ ions are stabilized by the oxygen atoms of carbonyl groups and fluorine atoms 5 of $\left[\mathrm{BF}_{4}\right]^{-}$anion. NBO and QTAIM analyses show that the $\mathrm{Ca}^{2+} \bullet \bullet \mathrm{O}$ interactions are far 6 stronger than $\mathrm{Ca}^{2+} \bullet \bullet \mathrm{F}$ interactions. QTAIM analysis and noncovalent interaction (NCI) plots 7 also reveal that these interactions $\left(\mathrm{Ca}^{2+} \bullet \bullet \mathrm{O}\right.$ and $\left.\mathrm{Ca}^{2+} \bullet \bullet \mathrm{F}\right)$ are strong and electrostatic in nature. 8 The calculated infrared (IR) frequencies of carbonyl groups $(\mathrm{C}=\mathrm{O})$ in the carbonate solvents 9 and their complexes show that the stretching frequency of $\mathrm{C}=\mathrm{O}$ groups become red-shifted 10 after binding with $\mathrm{Ca}^{2+}$ ion. These changes are consistent with the bond length extension and a 11 decrease in electron density in the $\mathrm{C}=\mathrm{O}$ groups. Electronic structure calculations show that the $12 \mathrm{E}_{\mathrm{g}}, \mu$ and $\eta$ values of carbonate solvents decrease upon interaction with $\mathrm{Ca}^{2+}$ ion and addition 13 of EC solvent, which in turn increases the reactivity of carbonate solvents. Furthermore, the 14 electrophilic nature of carbonate solvents increases with $\mathrm{Ca}^{2+}$ ion complexation and addition 15 of EC solvent. This simplifies the attainment of additional electronic charge from the 16 environment. The results of this study provide deeper insight into the rational design and 17 selection of novel electrolytes required for a feasible Ca-ion battery.

\section{Acknowledgement}

20 The authors would like to thank Madison Trozzi, and the Windsor SMArt (Science Meets Art) 21 initiative at the University of Windsor for the design and creation of the table of contents 22 graphic. This investigation was supported by the Iran National Science Foundation. SMT and 23 JFT would like to thank the Compute Canada for providing the facilities of the Shared 24 Hierarchical Academic Research Computing Network (SHARCNET: www.sharcnet.ca) to 25 support this project. This work was funded by the Natural Sciences and Engineering Research 26 Council of Canada grants\# 2018-06338, and 519843-17 to JFT.

\section{Supporting Information}

29 This material contains the structure of various nonaqueous organic electrolytes and

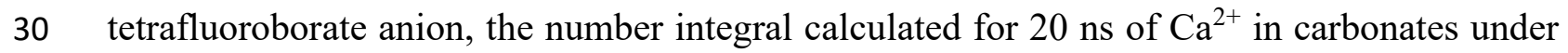
31 NPT conditions at $\mathrm{T}=300 \mathrm{~K}$ and $\mathrm{P}=1 \mathrm{bar}$, the population of the cluster size of the 
$1 \mathrm{Ca}^{2+}{ }^{\circ} \cdot$ carbonate solvent complexes, radial distribution function showing the interaction of

2 calcium ion with the tetrafluoroborate anion, the radial distribution function $\mathrm{g}(\mathrm{r})$ as a function

3 of cation-anion distance for $\mathrm{Li}^{+}, \mathrm{Na}^{+}, \mathrm{Mg}^{2+}$ and $\mathrm{Ca}^{2+}$ ions with the $\mathrm{PF}_{6}^{-}, \mathrm{ClO}_{4}{ }^{-}$and $\mathrm{BF}_{4}^{-}$anions,

4 the optimized geometries of the $\mathrm{Ca}^{2+}$-ion complexes with the pure and binary mixtures of

5 carbonate solvents, structural parameters, the results of QTAIM analysis, plots of the frontier

6 molecular orbitals, infrared (IR) spectra of the $\mathrm{Ca}^{2+} \cdot{ }^{2}$ carbonate solvent complexes, the noncovalent interaction plots, the electronic properties and global molecular descriptors of

8 carbonate solvents and their complexes with $\mathrm{Ca}^{2+}$ ion and a comparison of the electron density values at the bond critical points of the complexes.

\section{References}

(1) Scrosati, B.; Garche, J. Lithium batteries: Status, prospects and future. J. Power Sources 2010, 195, 2419-2430.

(2) Liu, C.; Li, F.; Ma, L.-P.; Cheng, H.-M. Advanced materials for energy storage. Adv. Mater. (Weinheim, Ger.) 2010, 22, E28-E62.

(3) Sun, X.; Hao, H.; Zhao, F.; Liu, Z. Global lithium flow 1994-2015: Implications for improving resource efficiency and security. Environ. Sci. Technol. 2018, 52, 2827-2834.

(4) Singh, N.; Arthur, T. S.; Ling, C.; Matsui, M.; Mizuno, F. A high energy-density tin anode for rechargeable magnesium-ion batteries. Chem. Commun. 2013, 49, 149-151.

(5) Xu, C.; Li, B.; Du, H.; Kang, F. Energetic zinc ion chemistry: The rechargeable zinc ion battery. Angew. Chem. Int. Ed. 2011, 51, 933-935.

(6) Jayaprakash, N.; Das, S. K.; Archer, L. A. The rechargeable aluminum-ion battery. Chem. Commun. 2011, 47, 12610-12612.

(7) Muldoon, J.; Bucur, C. B.; Gregory, T. Quest for nonaqueous multivalent secondary batteries: Magnesium and beyond. Chem. Rev. 2014, 114, 11683-11720.

(8) Wang, W.; Jiang, B.; Xiong, W.; Sun, H.; Lin, Z.; Hu, L.; Tu, J.; Hou, J.; Zhu, H.; Jiao, S. A new cathode material for super-valent battery based on aluminium ion intercalation and deintercalation. Sci. Rep. 2013, 3, 3383.

(9) Gummow, R. J.; Vamvounis, G.; Kannan, M. B.; He, Y. Calcium-ion batteries: Current state-of-the-art and future perspectives. Adv. Mater. (Weinheim, Ger.) 2018, 30, 1801702.

(10) Alekseenko, V.; Alekseenko, A. The abundances of chemical elements in urban soils. J. Geochem. Explor. 2014, 147, 245-249.

(11) Amatucci, G. G.; Badway, F.; Singhal, A.; Beaudoin, B.; Skandan, G.; Bowmer, T.; Plitz, I.; Pereira, N.; Chapman, T.; Jaworski, R. Investigation of yttrium and polyvalent ion intercalation into nanocrystalline vanadium oxide. J. Electrochem. Soc. 2001, 148, A940-A950.

(12) Pereira-Ramos, J. P.; Messina, R.; Perichon, J. Electrochemical formation of vanadium pentoxide bronzes $\mathrm{M}_{\mathrm{x}} \mathrm{V}_{2} \mathrm{O}_{5}$ in molten dimethylsulfone. J. Electrochem. Soc. 1988, 135, 3050-3057.

(13) Lipson, A. L.; Pan, B.; Lapidus, S. H.; Liao, C.; Vaughey, J. T.; Ingram, B. J. Rechargeable Ca-ion batteries: A new energy storage system. Chem. Mater. 2015, 27, 8442-8447. 
(14) Arroyo-de Dompablo, M. E.; Krich, C.; Nava-Avendaño, J.; Palacín, M. R.; Bardé, F. In quest of cathode materials for $\mathrm{Ca}$ ion batteries: the $\mathrm{CaMO}_{3}$ perovskites ( $\mathrm{M}=\mathrm{Mo}, \mathrm{Cr}, \mathrm{Mn}, \mathrm{Fe}, \mathrm{Co}$, and Ni). Phys. Chem. Chem. Phys. 2016, 18, 19966-19972.

(15) Tojo, T.; Sugiura, Y.; Inada, R.; Sakurai, Y. Reversible calcium ion batteries using a dehydrated Prussian blue analogue cathode. Electrochim. Acta 2016, 207, 22-27.

(16) Ponrouch, A.; Tchitchekova, D.; Frontera, C.; Bardé, F.; Dompablo, M. E. A.-d.; Palacín, M. R. Assessing Si-based anodes for Ca-ion batteries: Electrochemical decalciation of $\mathrm{CaSi}_{2}$. Electrochem. Commun. 2016, 66, 75-78.

(17) Padigi, P.; Goncher, G.; Evans, D.; Solanki, R. Potassium barium hexacyanoferrate - A potential cathode material for rechargeable calcium ion batteries. J. Power Sources 2015, 273, 460464.

(18) Ponrouch, A.; Frontera, C.; Bardé, F.; Palacín, M. R. Towards a calcium-based rechargeable battery. Nat. Mater. 2015, 15, 169-172.

(19) Xu, K. Nonaqueous liquid electrolytes for lithium-based rechargeable batteries. Chem. Rev. 2004, 104, 4303-4418.

(20) Chen, Z.; Ren, Y.; Jansen, A. N.; Lin, C.-k.; Weng, W.; Amine, K. New class of nonaqueous electrolytes for long-life and safe lithium-ion batteries. Nat. Commun. 2013, 4, 1513.

(21) Ponrouch, A.; Marchante, E.; Courty, M.; Tarascon, J.-M.; Palacín, M. R. In search of an optimized electrolyte for Na-ion batteries. Energy Environ. Sci. 2012, 5, 8572-8583.

(22) Aurbach, D.; Talyosef, Y.; Markovsky, B.; Markevich, E.; Zinigrad, E.; Asraf, L.; Gnanaraj, J. S.; Kim, H.-J. Design of electrolyte solutions for Li and Li-ion batteries: A review. Electrochim. Acta 2004, 50, 247-254.

(23) Ponrouch, A.; Monti, D.; Boschin, A.; Steen, B.; Johansson, P.; Palacín, M. R. Nonaqueous electrolytes for sodium-ion batteries. J. Mater. Chem. A 2015, 3, 22-42.

(24) Besenhard, J. O.; Winter, M.; Yang, J.; Biberacher, W. Filming mechanism of lithiumcarbon anodes in organic and inorganic electrolytes. J. Power Sources 1995, 54, 228-231.

(25) Yuan, K.; Bian, H.; Shen, Y.; Jiang, B.; Li, J.; Zhang, Y.; Chen, H.; Zheng, J. Coordination number of $\mathrm{Li}^{+}$in nonaqueous electrolyte solutions determined by molecular rotational measurements. J. Phys. Chem. B 2014, 118, 3689-3695.

(26) Eshetu, G. G.; Bertrand, J.-P.; Lecocq, A.; Grugeon, S.; Laruelle, S.; Armand, M.; Marlair, G. Fire behavior of carbonates-based electrolytes used in $\mathrm{Li}$-ion rechargeable batteries with a focus on the role of the LiPF 6 and LiTFSI salts. J. Power Sources 2014, 269, 804-811.

(27) Wu, S.; Zhang, F.; Tang, Y. A novel calcium-ion battery based on dual-carbon configuration with high working voltage and long cycling life. Adv. Sci. 2018, 5, 1701082.

(28) Jiang, B.; Ponnuchamy, V.; Shen, Y.; Yang, X.; Yuan, K.; Vetere, V.; Mossa, S.; Skarmoutsos, I.; Zhang, Y.; Zheng, J. The anion effect on $\mathrm{Li}^{+}$ion coordination structure in ethylene carbonate solutions. J. Phys. Chem. Lett. 2016, 7, 3554-3559.

(29) Skarmoutsos, I.; Ponnuchamy, V.; Vetere, V.; Mossa, S. $\mathrm{Li}^{+}$solvation in pure, binary, and ternary mixtures of organic carbonate electrolytes. J. Phys. Chem. C 2015, 119, 4502-4515.

(30) Shakourian-Fard, M.; Kamath, G.; Sankaranarayanan, S. K. R. S. Evaluating the free energies of solvation and electronic structures of lithium-ion battery electrolytes. ChemPhysChem 2016, 17, 2916-2930.

(31) Kamath, G.; Cutler, R. W.; Deshmukh, S. A.; Shakourian-Fard, M.; Parrish, R.; Huether, J.; Butt, D. P.; Xiong, H.; Sankaranarayanan, S. K. R. S. In silico based rank-order determination and experiments on nonaqueous electrolytes for sodium ion battery applications. J. Phys. Chem. C 2014, 118, 13406-13416. 
(32) Shakourian-Fard, M.; Kamath, G.; Smith, K.; Xiong, H.; Sankaranarayanan, S. K. R. S. Trends in Na-ion solvation with alkyl-carbonate electrolytes for sodium-ion batteries: Insights from first-principles calculations. J. Phys. Chem. C 2015, 119, 22747-22759.

(33) Shakourian-Fard, M.; Kamath, G.; Sankaranarayanan, S. K. R. S. Electronic structure insights into the solvation of magnesium ions with cyclic and acyclic carbonates. ChemPhysChem 2015, 16, 3607-3617.

(34) Aurbach, D.; Skaletsky, R.; Gofer, Y. The electrochemical behavior of calcium electrodes in a few organic electrolytes. J. Electrochem. Soc. 1991, 138, 3536-3545.

(35) Bogle, X.; Vazquez, R.; Greenbaum, S.; Cresce, A. v. W.; Xu, K. Understanding Li+solvent interaction in nonaqueous carbonate electrolytes with 170 NMR. J. Phys. Chem. Lett. 2013, 4, 1664-1668.

(36) O'Gara, J. F.; Nazri, G.; MacArthur, D. M. A carbon-13 and lithium-6 nuclear magnetic resonance study of lithium perchlorate/poly (ethylene oxide) electrolytes. Solid State Ionics 1991, 47, 87-96.

(37) Fukushima, T.; Matsuda, Y.; Hashimoto, H.; Arakawa, R. Solvation of lithium ions in organic electrolytes of primary lithium batteries by electrospray ionization-mass spectroscopy. J. Power Sources 2002, 110, 34-37.

(38) Bhatt, M. D.; Cho, M.; Cho, K. Interaction of Li+ ions with ethylene carbonate (EC): Density functional theory calculations. Appl. Surf. Sci. 2010, 257, 1463-1468.

(39) Sekhon, S. S.; Deepa; Agnihotry, S. A. Solvent effect on gel electrolytes containing lithium salts. Solid State Ionics 2000, 136-137, 1189-1192.

(40) Borodin, O.; Smith, G. D. Quantum chemistry and molecular dynamics simulation study of dimethyl carbonate: Ethylene carbonate electrolytes doped with LiPF. J. Phys. Chem. B 2009, 113, 1763-1776.

(41) Bhatt, M. D.; O'Dwyer, C. Density functional theory calculations for ethylene carbonate-based binary electrolyte mixtures in lithium ion batteries. Curr. Appl. Phys. 2014, 14, 349354.

(42) Borodin, O.; Smith, G. D. LiTFSI structure and transport in ethylene carbonate from molecular dynamics simulations. J. Phys. Chem. B 2006, 110, 4971-4977.

(43) Silva, L. B.; Freitas, L. C. G. Structural and thermodynamic properties of liquid ethylene carbonate and propylene carbonate by Monte Carlo simulations. J. Mol. Struct.: THEOCHEM 2007, 806, 23-34.

(44) Vanommeslaeghe, K.; Hatcher, E.; Acharya, C.; Kundu, S.; Zhong, S.; Shim, J.; Darian, E.; Guvench, O.; Lopes, P.; Vorobyov, I. et al. CHARMM general force field: A force field for drug-like molecules compatible with the CHARMM all-atom additive biological force fields. J. Comput. Chem. 2009, 31, 671-690.

(45) Hénin, J.; Fiorin, G.; Chipot, C.; Klein, M. L. Exploring multidimensional free energy landscapes using time-dependent biases on collective variables. J. Chem. Theory Comput. 2010, 6, 35-47.

(46) Frisch, M. J.; Trucks, G. W.; Schlegel, H. B.; Scuseria, G. E.; Robb, M. A.; Cheeseman, J. R.; Scalmani, G.; Barone, V.; Mennucci, B.; Petersson, G. A. et al. Gaussian 09; Gaussian, Inc.: Wallingford, CT, USA, 2009.

(47) Zhao, Y.; Schultz, N. E.; Truhlar, D. G. Design of density functionals by combining the method of constraint satisfaction with parametrization for thermochemistry, thermochemical kinetics, and noncovalent interactions. J. Chem. Theory Comput. 2006, 2, 364-382.

(48) Zhao, Y.; Truhlar, D. G. The M06 suite of density functionals for main group thermochemistry, thermochemical kinetics, noncovalent interactions, excited states, and transition 
elements: two new functionals and systematic testing of four M06-class functionals and 12 other functionals. Theor. Chem. Acc. 2008, 120, 215-241.

(49) Borodin, O.; Olguin, M.; Spear, C.; Leiter, K.; Knap, J.; Yushin, G.; Childs, A.; Xu, K. Challenges with quantum chemistry-based screening of electrochemical stability of lithium battery electrolytes. ECS Trans. 2015, 69, 113-123.

(50) Johnson, E. R.; Wolkow, R. A.; DiLabio, G. A. Application of 25 density functionals to dispersion-bound homomolecular dimers. Chem. Phys. Lett. 2004, 394, 334-338.

(51) Tsuzuki, S.; Lüthi, H. P. Interaction energies of van der Waals and hydrogen bonded systems calculated using density functional theory: Assessing the PW91 model. J. Chem. Phys. 2001, 114, 3949-3957.

(52) Boys, S. F.; Bernardi, F. The calculation of small molecular interactions by the differences of separate total energies. Some procedures with reduced errors. Mol. Phys. 1970, 19, 553-566.

(53) Reed, A. E.; Curtiss, L. A.; Weinhold, F. Intermolecular interactions from a natural bond orbital, donor-acceptor viewpoint. Chem. Rev. 1988, 88, 899-926.

(54) Reed, A. E.; Weinhold, F. Natural localized molecular orbitals. J. Chem. Phys. 1985, 83, 1736-1740.

(55) Harper, L. K.; Shoaf, A. L.; Bayse, C. A. Predicting trigger bonds in explosive materials through Wiberg bond index analysis. ChemPhysChem 2015, 16, 3886-3892.

(56) Wiberg, K. B. Application of the Pople-Santry-Segal CNDO method to the cyclopropylcarbinyl and cyclobutyl cation and to bicyclobutane. Tetrahedron 1968, 24, 1083-1096.

(57) Bader, R. F. W. Atoms in molecules, a quantum theory; Oxford Univeristy Press: Oxford, 1990.

(58) Biegler-Konig, F.; Schonbohm, J.; Bayles, D. AIM2000. J. Comput. Chem. 2001, 22, 545-559.

(59) Lu, T.; Chen, F. Multiwfn: A multifunctional wavefunction analyzer. J. Comput. Chem. 2011, 33, 580-592.

(60) Humphrey, W.; Dalke, A.; Schulten, K. VMD: Visual molecular dynamics. J. Mol. Graph. 1996, 14, 33-38.

(61) Geerlings, P.; De Proft, F.; Langenaeker, W. Conceptual density functional theory. Chem. Rev. 2003, 103, 1793-1874.

(62) Roy, R. K.; Saha, S. Studies of regioselectivity of large molecular systems using DFT based reactivity descriptors. Ann. Rep. Prog. Chem., Sect. C: Phys. Chem. 2010, 106, 118-162.

(63) Parr, R. G.; Pearson, R. G. Absolute hardness: Companion parameter to absolute electronegativity. J. Am. Chem. Soc 1983, 105, 7512-7516.

(64) Koopmans, T. Über die zuordnung von wellenfunktionen und eigenwerten zu den einzelnen elektronen eines atoms. Physica 1934, 1, 104-113.

(65) Walker, M.; Harvey, A. J. A.; Sen, A.; Dessent, C. E. H. Performance of M06, M06-2X, and M06-HF density functionals for conformationally flexible anionic clusters: M06 functionals perform better than B3LYP for a model system with dispersion and ionic hydrogen-bonding interactions. J. Phys. Chem. A 2013, 117, 12590-12600.

(66) Tchitchekova, D. S.; Monti, D.; Johansson, P.; Bardé, F.; Randon-Vitanova, A.; Palacín, M. R.; Ponrouch, A. On the reliability of half-cell tests for monovalent $\left(\mathrm{Li}^{+}, \mathrm{Na}^{+}\right)$and divalent $\left(\mathrm{Mg}^{2+}, \mathrm{Ca}^{2+}\right)$ cation based batteries. J. Electrochem. Soc. 2017, 164, A1384-A1392.

(67) Okoshi, M.; Yamada, Y.; Yamada, A.; Nakai, H. Theoretical analysis on de-solvation of lithium, sodium, and magnesium cations to organic electrolyte solvents. J. Electrochem. Soc. 2013, 160, A2160-A2165. 
1

(68) Cresce, A. V.; Russell, S. M.; Borodin, O.; Allen, J. A.; Schroeder, M. A.; Dai, M.; Peng, J.; Gobet, M. P.; Greenbaum, S. G.; Rogers, R. E. et al. Solvation behavior of carbonate-based electrolytes in sodium ion batteries. Phys. Chem. Chem. Phys. 2017, 19, 574-586.

(69) Zhang, B.; Zhou, Y.; Li, X.; Ren, X.; Nian, H.; Shen, Y.; Yun, Q. Ion-molecule interaction in solutions of lithium tetrafluoroborate in propylene carbonate: An FTIR vibrational spectroscopic study. Int. J. Electrochem. Sci. 2013, 12, 12735-12740.

(70) Johnson, E. R.; Keinan, S.; Mori-Sánchez, P.; Contreras-García, J.; Cohen, A. J.; Yang, W. Revealing noncovalent interactions. J. Am. Chem. Soc. 2010, 132, 6498-6506.

(71) Seo, D. M.; Reininger, S.; Kutcher, M.; Redmond, K.; Euler, W. B.; Lucht, B. L. Role of mixed solvation and ion pairing in the solution structure of lithium ion battery electrolytes. J. Phys. Chem. C 2015, 119, 14038-14046. 